\title{
Satellite Remote Sensing of Surface Urban Heat Islands: Progress, Challenges, and Perspectives
}

\author{
Decheng Zhou ${ }^{1, *(\mathbb{D}}$, Jingfeng Xiao ${ }^{2, *} \mathbb{\infty}$, Stefania Bonafoni ${ }^{3}\left(\mathbb{C}\right.$, Christian Berger $^{4}(\mathbb{D}$, \\ Kaveh Deilami ${ }^{5}{ }^{\circledR}$, Yuyu Zhou ${ }^{6}{ }^{\circ}$, Steve Frolking ${ }^{2}$, Rui Yao ${ }^{7}$, Zhi Qiao ${ }^{8}$ and José A. Sobrino ${ }^{9}$
}

1 Jiangsu Key Laboratory of Agricultural Meteorology, Nanjing University of Information Science and Technology, Nanjing 210044, China

2 Earth Systems Research Center, Institute for the Study of Earth, Oceans, and Space, University of New Hampshire, Durham, NH 03824, USA; steve.frolking@unh.edu

3 Department of Engineering, University of Perugia, via G. Duranti 93, 06125 Perugia, Italy; stefania.bonafoni@unipg.it

4 Department for Earth Observation, Friedrich-Schiller-Universität Jena, Löbdergraben 32, 07743 Jena, Germany; christian.berger@uni-jena.de

5 School of Earth and Environmental Sciences, The University of Queensland, Brisbane, QLD 4072, Australia; k.deilami@uq.edu.au

6 Department of Geological and Atmospheric Sciences, Iowa State University, Ames, IA, USA 50011; yuyuzhou@iastate.edu

7 Laboratory of Critical Zone Evolution, School of Earth Sciences, China University of Geosciences, Wuhan 430074, China; 1201610162@cug.edu.cn

8 Key Lab. of Indoor Air Environment Quality Control, School of Environmental Science and Engineering, Tianjin University, Weijin Road 92, Tianjin 300072, China; qiaozhi@tju.edu.cn

9 Global Change Unit, Department of Thermodynamics, Faculty of Physics, University of Valencia, E-46071 Valencia, Spain; Jose.Sobrino@uv.es

* Correspondence: zhoudc@nuist.edu.cn (D.Z.); j.xiao@unh.edu (J.X.); Tel.: +86-25-58731539 (D.Z.); +1-603-862-1873 (J.X.)

Received: 4 December 2018; Accepted: 24 December 2018; Published: 29 December 2018

\begin{abstract}
The surface urban heat island (SUHI), which represents the difference of land surface temperature (LST) in urban relativity to neighboring non-urban surfaces, is usually measured using satellite LST data. Over the last few decades, advancements of remote sensing along with spatial science have considerably increased the number and quality of SUHI studies that form the major body of the urban heat island (UHI) literature. This paper provides a systematic review of satellite-based SUHI studies, from their origin in 1972 to the present. We find an exponentially increasing trend of SUHI research since 2005, with clear preferences for geographic areas, time of day, seasons, research foci, and platforms/sensors. The most frequently studied region and time period of research are China and summer daytime, respectively. Nearly two-thirds of the studies focus on the SUHI/LST variability at a local scale. The Landsat Thematic Mapper (TM)/Enhanced Thematic Mapper (ETM+)/Thermal Infrared Sensor (TIRS) and Terra/Aqua Moderate Resolution Imaging Spectroradiometer (MODIS) are the two most commonly-used satellite sensors and account for about $78 \%$ of the total publications. We systematically reviewed the main satellite/sensors, methods, key findings, and challenges of the SUHI research. Previous studies confirm that the large spatial (local to global scales) and temporal (diurnal, seasonal, and inter-annual) variations of SUHI are contributed by a variety of factors such as impervious surface area, vegetation cover, landscape structure, albedo, and climate. However, applications of SUHI research are largely impeded by a series of data and methodological limitations. Lastly, we propose key potential directions and opportunities for future efforts. Besides improving the quality and quantity of LST data, more attention should be focused on understudied regions/cities, methods to examine SUHI intensity, inter-annual variability and long-term trends of SUHI, scaling issues of SUHI, the relationship between surface and subsurface UHIs, and the integration of remote sensing with field observations and numeric modeling.
\end{abstract}


Keywords: thermal remote sensing; land surface temperature; urban heat island; urbanization; review; impervious surface; MODIS; Landsat; ASTER; heat waves

\section{Introduction}

The urban heat island (UHI) - a phenomenon in which temperature tends to be higher in urban zones than surrounding non-urban areas-represents a major anthropogenic alteration to the Earth's environments [1]. The UHI phenomenon has been observed worldwide [2-6]. It has been widely attributed to the change in the energy exchange between urban land surfaces and the atmosphere, which is primarily caused by increased impervious surface cover replacing evaporative vegetation surfaces, and by anthropogenic heat releases [1,7]. The UHI has contributed to a suite of environmental changes such as regional climate [8-10], vegetation growth [11,12], and water and air quality [13]. These factors, in turn, affect human health and well-being dramatically and may potentially lead to increases in morbidity and mortality [14], energy consumption [15], and even violent incidents [16] in urban areas, which are home to 55\% of the world's population today [17]. The UHI effect and the associated consequences are expected to be more severe under a warming climate [10] and a rapidly urbanizing world [18]. This is particularly true in China, India, and Nigeria, which are projected to occupy 35\% of the global urban population growth between 2018 and 2050 [17]. UHI, therefore, has gained considerable research interest and has been the subject of active investigation, especially in the last decade.

Intensive studies have been conducted to understand UHI, which, in general, can be classified into two broad categories based on the ways and heights that they are formed [1]: "air" (or "atmospheric") and "surface" UHIs. Air UHI refers to UHI effects in the canopy (CLHI) or boundary (BLHI) layer. The CLHI is usually measured by in situ sensors mounted on fixed meteorological stations or traverses of vehicles [19-22], while more special platforms such as tall towers, radiosondes, and aircraft are needed to measure the BLHI [23]. The development and installation of these measurement devices are usually very time-consuming and expensive, and, thus, are only available in a few large cities worldwide to date [24]. Due to limited monitoring stations, the measured air UHIs usually fail to provide sufficient spatial details for urban land use planning and climate change research [25-28]. In contrast, the surface UHI (SUHI), which represents the radiative temperature difference between urban and non-urban surfaces, is primarily measured by satellite thermal remote sensing data [29]. It can provide consistent and repeatable observations of the Earth's surface, which offers the ability to study the urban thermal environment at various spatial (from local to global scales) and temporal (diurnal, seasonal, and inter-annual) scales [28,30]. It can also be used to predict air UHI in a spatially-explicit manner [31,32] (see Section 5.4). Rao [33] reported in 1972 the first satellite-based observations of the SUHI phenomenon in the Eastern United States. Since then, advancements in remote sensing and spatial science have considerably boosted the number and quality of SUHI studies, which currently form the major body of the UHI literature. A thorough knowledge of past literature on SUHI can not only provide a basis for future research but also is crucial for formulating effective UHI mitigation and adaptation strategies.

Previous reviews of SUHI research have concentrated mostly on summarizing the methods, applications, and limitations of thermal remote sensing techniques based on representative literature [28,29,34-36] and/or a more general topic that only partially covered SUHI [7,8,24,37]. For example, Gallo et al. [34] reviewed several satellite-based SUHI studies between 1972 and 1993 and emphasized the application of Normalized Difference Vegetation Index (NDVI) data in SUHI research. Arnfield [8] compared different types of UHI briefly while synthesizing progress in urban climatology during the 1980s and 1990s. Voogt and Oke [29] focused on the principles of thermal remote sensing, the relationship between surface and air UHIs, and the potential use of thermal remote sensing data in urban climate models. Rizwan et al. [7] presented a systematic review of the generation as well 
as determination and mitigation of UHI based mainly on air UHI studies. Weng [28] reviewed the methods and applications of thermal remote sensing, but concentrated on land surface temperature (LST) retrieval, LST-vegetation relationships, and some typical applications of thermal infrared remote sensing data in SUHI studies. Huang and Lu [37] examined the literature trends of UHI research from 1991 to 2015 using bibliometric methods, regardless of UHI types. The most recent work by Deilami et al. [30] focused solely on SUHI, but reviewed only the spatial and temporal factors affecting the SUHI based on the publications after 2007. We extend this review literature by conducting a systematic review of the features, current status, and prospects of SUHI research.

This study aims to provide a comprehensive and broad review on the SUHI studies from their origin in 1972 to the present. The specific objectives of this review are to: (1) explore the characteristics of research output on SUHI, (2) review the space borne sensors and methods employed to measure the SUHI, and (3) outline the key research findings, challenges, and potential future directions of the SUHI research. The current review concentrates on the satellite-based SUHI studies, even though airborne sensors were also used to study SUHI in several cities. Our review will provide important insights not only for scientists on understanding the SUHI phenomenon, but also for practitioners to formulate the associated mitigation and adaptation strategies.

\section{Historical Review}

This section presents a historical review of SUHI studies via satellite data from their origin nearly 50 years ago to the present. The characteristics of research output including the historical trend, geographic areas, study time-of-day and season, and research foci were examined using a set of descriptive statistics of a carefully screened collection of the SUHI literature. The key milestones in remote sensing of SUHIs are then summarized.

\subsection{Characteristics of Research Output}

\subsubsection{Criteria Used to Select Literature}

We searched for research articles published in peer-reviewed journals in English from 1972 to August 2018 using the ISI Web of Science and Google Scholar databases. The following two combinations of keywords were used to collect the literature: (1) "urban heat island OR urban thermal environment OR urban climate" AND "remote sensing OR satellite OR MODIS OR Landsat OR AVHRR OR ASTER OR ATSR OR SEVIRI OR HCMM", and (2) "land surface temperature OR thermal environment" AND "urbanization OR urban land OR land use change OR land cover change OR cities OR city OR metropolitan area". The search yielded a total of $>3000$ journal publications. These were screened to check whether they studied urban surface temperature or thermal environment by reading the publication title and abstract. The screening resulted in 778 publications. All these papers were then downloaded and more carefully read to examine whether the publications (1) used satellite images to derive LST, and (2) explored the temperature variations in an urban environment. Studies that focused solely on LST retrieval (see reviews by Li et al. [38] and Mohamed et al. [39]) and downscaling methods [40,41], air UHI (see reviews by Unger [42], Stewart [43], Mirzaei [44], and Chapman, et al. [45]), and UHI mitigation strategies (see reviews by Gago et al. [46], Santamouris [47], Larsen [48], and Jamei et al. [49]) were not included in our literature analysis. This full-text check resulted in 492 eligible publications (references of all studies are listed in the Supplementary Materials and Table S1). All of the information, including the title, author, source journal, publication year, sensor types, study area, study time, and research foci, was extracted for further analysis. 


\subsubsection{Historical Trend}

While Rao [33] first observed the SUHI phenomenon in 1972, SUHI research was not a highly active field between 1972 and 2005, with less than five studies published per year (Figure 1). SUHI publications started to grow exponentially in 2005. The number of studies from 2006 to 2010 was $40 \%$ higher than the total number of publications from 1972 to 2005 (74 vs. 53). The growth rate has continued to increase, with more than 75 articles published in recent years. This increase can be attributed, on one hand, to the increasing interest in this area associated with rapid urbanization [17] and global warming [10]. On the other hand, advancements of remote sensing techniques and computing power have dramatically enhanced the quantity and quality of remote sensing data, and, therefore, contributed to increased SUHI research [28]. In particular, the freely-available Landsat series data since 2008 and MODIS data have largely reduced the research costs in recent years.

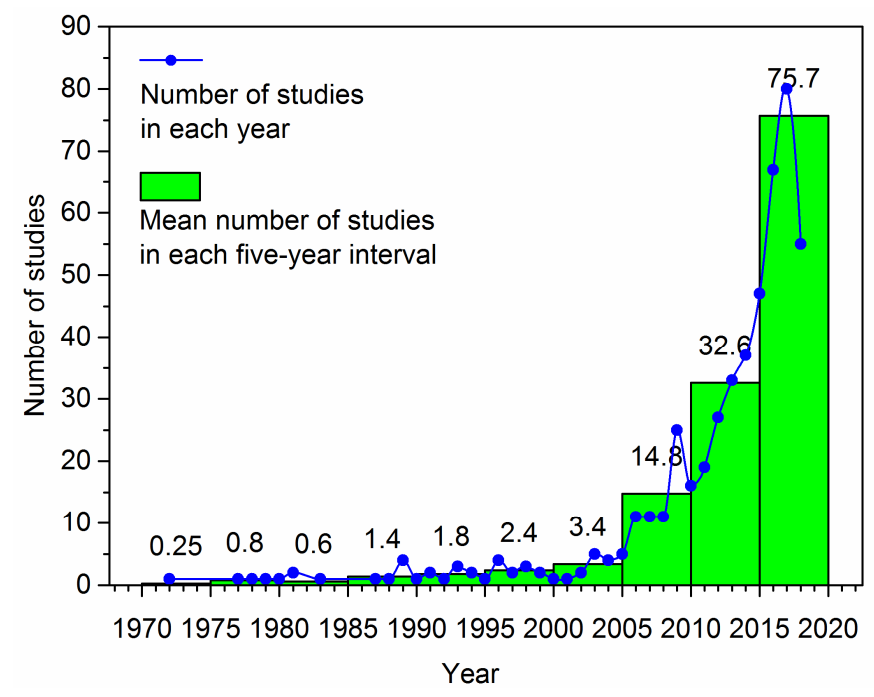

Figure 1. Number of studies in each year and the mean number of publications in each five-year interval. Note that the final year (2018) has data only for eight months (January-August).

\subsubsection{Geographic Patterns}

There has been a large geographic bias of the cities being studied (Figure 2). The selected literature has focused predominantly on Asia (62\%). North America had the next largest number of studies (24\%), which was followed by Europe (15\%). There has been relatively little SUHI research in Africa, South and Central America, and Oceania, with $<37$ publications, and these cities were mostly included in global-scale studies rather than having a particular focus. Studies on all continents increased dramatically through time, especially after 2010. North America dominated the SUHI literature before 2000 while Asia became the major focus thereafter. A country-based analysis indicates that China was the most actively-studied country of SUHI research (213), which was followed by the United States (106) and India (38). The high fraction of studies in China is due to the large number of Chinese researchers publishing on the subject. About 91\% (194) of the studies on Chinese cities are led by Chinese scientists. Furthermore, a city-based analysis demonstrates that the SUHI was studied in more than 1400 cities worldwide, particularly in Chinese cities such as Beijing (72), Shanghai (51), Nanjing (35), Guangzhou (33), and Wuhan (32). The top 20 cities were nearly all in China. Indianapolis (22) and Phoenix (21) were the most active research sites in the United States. Paris (11) and Berlin (11) were the most active research sites in Europe, and Sao Paulo (5), Lagos (5), and Sydney (4) were the most active sites in South America, Africa, and Oceania, respectively. 

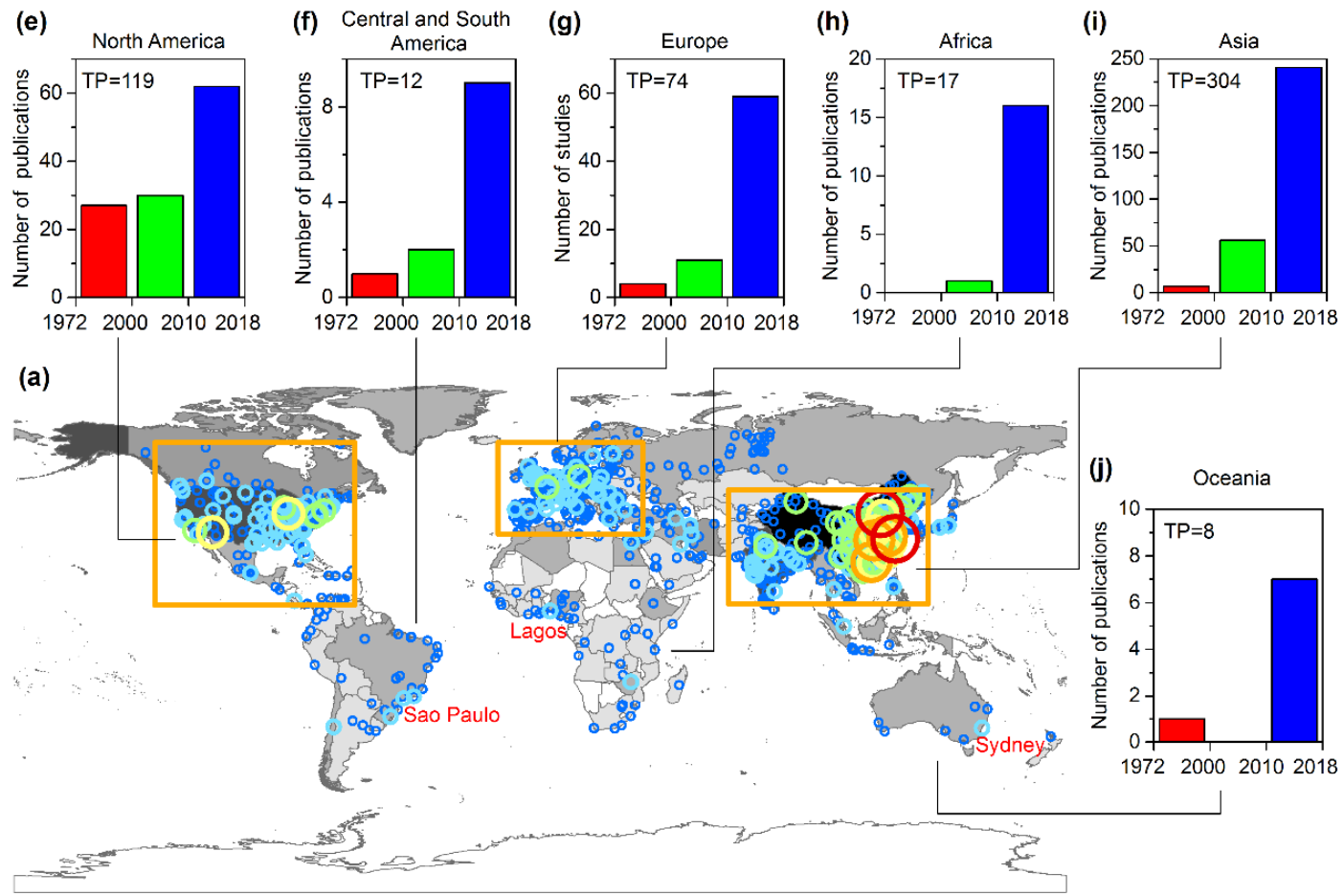

(b)

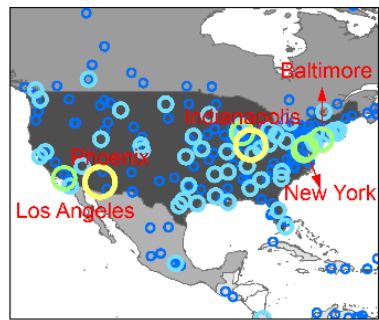

Number of publications in each city

- $1-3$

- $4-10$ (c)

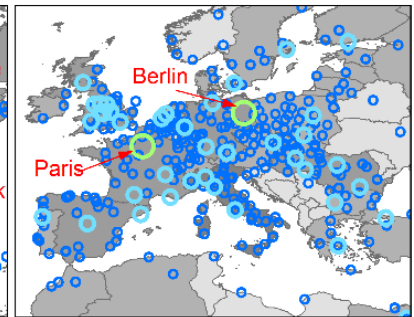

(d)

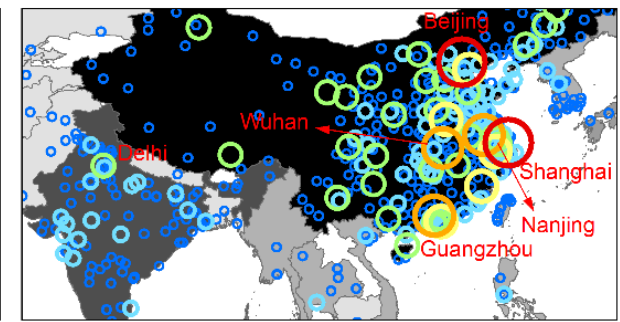

Number of publications in each country

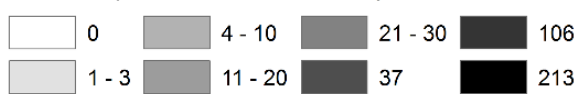

Figure 2. Geographic distribution of the selected SUHI literature based on the study location. (a) The number of studies per city (empty cycle) and country (background color), (b-d) the enlarged view of the SUHI publications in North America, Europe, and Asia, and (e-j) the number of publications in each continent. One study may cover a series of cities distributed in different countries and/or continents. Two global-scale studies [2,50] were not included in this summary since they did not specify the studied cities. Three regional-scale studies $[3,5,51]$ were not counted in the number of publications in each city (panels a to d) because they focused on the SUHIs of all cities in spite of city size. TP represents the total publications in each continent.

\subsubsection{The Study Time of Day and Season}

There are strong biases in the study time of day and season of the selected SUHI literature. The majority of the research $(69 \%)$ concentrated on the SUHI at a single time, especially the daytime $(63 \%)$, while only $30 \%$ of the studies explored the SUHI during the day and night (Figure 3a). Furthermore, the data acquisition times of sun-synchronous satellites usually do not coincide with the time of day where the LST is at a minimum or maximum. With regard to the season, over half of the literature (55\%) focused on the SUHI in an individual season, particularly summer (33\%), and only $23 \%$ of the studies investigated the SUHI in all seasons (Figure $3 b)$. Most of the remaining studies (18\%) examined the SUHI in multiple seasons or used multi-season LST data due to data limitation. A few studies (4\%) focused on annual mean SUHI or did not provide information on the season examined. 

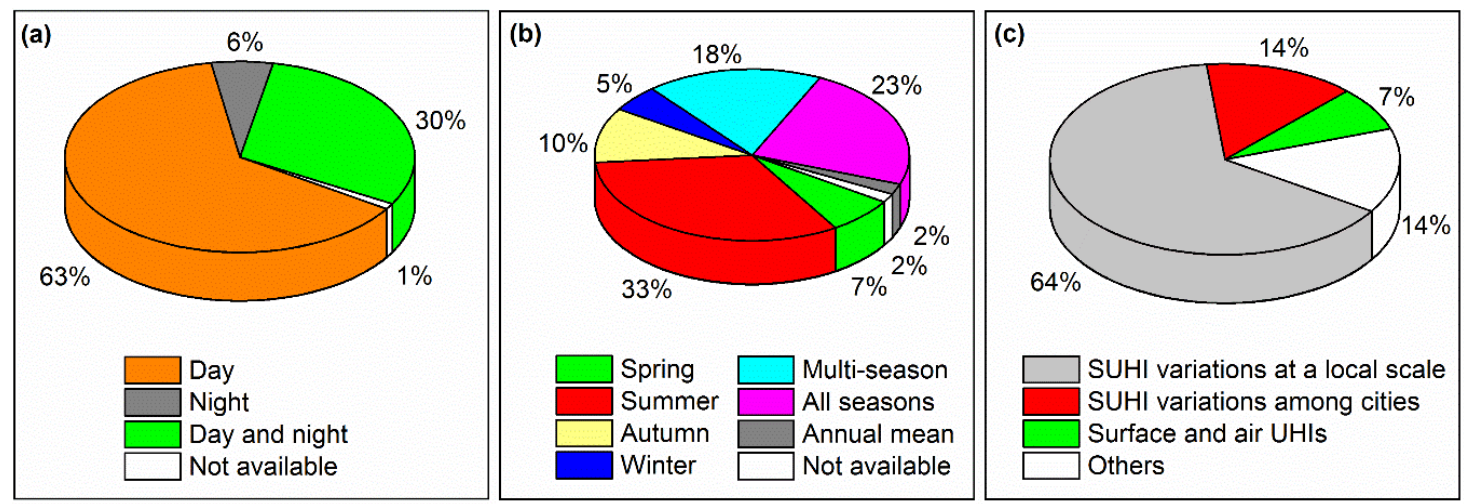

Figure 3. The study time of day (a), season (b), and foci (c) of the selected SUHI studies.

These temporal biases of SUHI research can be attributed to data limitations, and varying magnitudes of SUHI over time. On one hand, the most widely used satellite for SUHI detection (i.e., Landsat) only has daytime data. Additionally, thermal infrared images are strongly influenced by weather conditions, especially cloud cover, which result in a significant missing-data problem. More details on data limitations can be found in Section 6 below. On the other hand, the SUHI together with its adverse effects (e.g., heat stress) have been widely found to be most intense during the day in the summertime $[4,6,52]$. Therefore, this attracts greater research interest. However, several studies have confirmed that SUHI intensity and the underlying mechanisms vary dramatically through time $[4,6,53]$, which highlights the necessity of more comprehensive evaluations on SUHIs across different times of day and seasons. For example, the LST spatiotemporal fusion schemes hold great potential to address this gap [54].

\subsubsection{Research Foci}

SUHI research has covered a wide range of topics, including SUHI variations at a local scale, SUHI variations among cities, the relationship between SUHI and air UHI, and others (Figure 3c). Local-scale SUHI variations were of the most interest to researchers (64\%). Impacts of urban expansion and landscape structure on the SUHI had similar coverage, which accounted for $18 \%$ and $17 \%$ of the total publications, respectively. In contrast, less attention (14\%) has been paid to the SUHI variations among cities at a regional or global scale. The correlations between surface and air UHIs have also become one of the most important topics of SUHI research $(8 \%)$ because of their contrasting observation altitudes and methods. The remaining literature $(14 \%)$ concentrated on other issues such as data quality, quantification methods, and health risks. These SUHI-related studies were published in 107 different journals, which suggests a wide variety of interests of scholars from various disciplines, particularly those in the fields of remote sensing, environment, urban landscape, and sustainability. Further details on the active journals can be found in Supporting Materials Text S1.

\subsection{Milestones in Remote Sensing of SUHI}

A series of milestones can be identified in the history of SUHI research in terms of data availability. P. Krishna Rao who is a research physical scientist of the National Environmental Satellite Service (NESS) of the National Oceanic and Atmospheric Administration (NOAA) was the forerunner to study SUHI using satellite thermal data. He found evident urban signatures on ITOS-1 thermal images in the Eastern United States, and highlighted the potential of thermal remote sensing in SUHI research [33]. This led to further SUHI research, but at a relatively coarse spatial resolution $(\sim 1.1 \mathrm{~km})$ and low accuracy through meteorological satellite imagery [55-57]. To facilitate the comparison analysis, high spatial (temporal) resolution data refer to the data with a resolution of $<120 \mathrm{~m}$ ( $<1$ day), while others are considered as coarse resolution data in this study. In 1990, Landsat data were first applied in SUHI research [58]. Even though only available in the daytime, the Landsat archive soon 
became the major satellite record for the SUHI analyses because of its comparatively high spatial resolution (60-120 m), long time series, and high data quality, especially after the free release of the entire Landsat archive in 2008. The Moderate Resolution Imaging Spectroradiometer (MODIS) LST product [59] constitutes another important data source for SUHI research due to its high temporal resolution, medium spatial resolution $(1 \mathrm{~km})$, global coverage, and free availability. MODIS enables the study of diurnal, inter-annual, and intra-annual variability of SUHI at various spatial scales. The standard MODIS LST data were initially released in 2000, while MODIS-based SUHI research was first published in English in 2004 [60]. Nichol [61] provided the first high-resolution ( $90 \mathrm{~m})$ study of SUHI during the day and night using the Advanced Spaceborne Thermal Emission and Reflection Radiometer (ASTER) data in 2005, even though the standard ASTER LST products has been available since 2001. The entire archive of ASTER data became available free of charge in 2016. Details of these data are reviewed in Section 3.

SUHI research has also been greatly advanced by a suite of breakthroughs in scientific knowledge. For example, Roth et al. [62] provided the first full discussion of the applications and limitations of thermal remote sensing in urban climate research. The metrological questions that they raised were then systematically reviewed by Voogt and Oke [29]. These two efforts provided critical overviews of the theoretic basis for studying SUHI. Gallo et al. [63] explored the relationship between SUHI and NDVI for the first time, which still constitutes one of the major indicators to measure the LST-vegetation relationship. Weng et al. [64] introduced the vegetation fraction, which is an alternative indicator of vegetation to SUHI research. They found that the vegetation fraction possessed a slightly stronger relationship with LST than NDVI in urban areas. Jin et al. [65] published the first study of the impacts of global urban areas on climate. Lu and Weng [66] explored the role of an impervious surface area (ISA) in influencing SUHI patterns for the first time, and this soon became one of the most widely studied land surface properties in SUHI research. Two years later, the landscape ecology methods were first applied in SUHI research [67]. Schwarz et al. [68] provided the first comprehensive comparison analysis of indicators for quantifying the SUHI intensity and emphasized the large uncertainties associated with the quantification methods. Recently, Hu et al. [69] made the first effort to evaluate the impact of directional anisotropy on the derived SUHI. They demonstrated that anisotropic effects can modify the SUHI by $25 \%$ to $50 \%$. All of these works have promoted rapid progress in SUHI research.

\section{Satellite Sensors for SUHI Studies}

The satellite era of UHI studies begins in 1972 [62]. Table 1 shows the proportion of the reviewed studies using different sensors/satellites imagery. Those sensors possess a common specification. The sensors are passive and, thus, receive and measure both reflected shortwave radiation (non-thermal spectral bands) and emitted longwave radiation (thermal bands) by the Earth's surface and atmosphere [39]. This is critical for SUHI studies as the understanding of drivers of SUHI is widely grounded in decoding the relationship between two key factors including the LST/SUHI intensity of a region and the associated underlying land cover/use composition and configuration. Remote sensing imagery is, thus, unique data for researchers to derive these factors for an entire city through processing a single data set (satellite imagery) [36]. In this subsection, we provide an overview of advantages and disadvantages of three satellite/sensors as the main data providers for SUHI studies (Landsat, MODIS, and ASTER). Less frequently used sensors such as AVHRR, SEVIRI, and GOES are not reviewed in this paper.

Table 1. Proportion of reviewed SUHI studies using various satellite images.

\begin{tabular}{ccccccc}
\hline Sensor & Landsat Series & MODIS & ASTER & Multiple Sensors & AVHRR & Others ${ }^{1}$ \\
\hline Proportion & $53 \%$ & $25 \%$ & $7 \%$ & $6 \%$ & $4 \%$ & $5 \%$ \\
\hline \multicolumn{7}{c}{ SEVIRI, GOES, HCMM, HJ-1B, AATSR, ITOS-1, COMS, FY-2F, AMSR-E, AMSR2. }
\end{tabular}




\subsection{Landsat}

As shown in Table 1, almost $53 \%$ of researchers have used either one or multiple Landsat images in their SUHI studies, which emphasized the importance of the Landsat constellation to the SUHI knowledge. Since the launch of Landsat in 1972, the satellite constellation has carried four generations of sensors including: (1) Multispectral Scanner (MSS) sensors, optical instruments, and video cameras aboard Landsat 1, 2, and 3, (2) MSS and Thematic Mapper (TM) sensors aboard Landsat 4 and 5 , (3) Enhanced Thematic Mapper Plus (ETM+) aboard Landsat 7, and (4) Operational Land Imager (OLI) and Thermal Infrared Sensor (TIRS) aboard Landsat 8 [70,71]. From the TM sensor onward since 1982 , the ability to measure thermal radiance and, thereby, the LST of the Earth's surface has made a breakthrough in investigating SUHI.

There are three main reasons for Landsat's popularity in SUHI studies. First, Landsat "is the longest running uninterrupted Earth observation program" [72]. Second, researchers, as a result of a policy change in 2008, can freely obtain Landsat images. These features, therefore, provide a consistent, reliable, and voluminous archive of data for researchers to explore different aspects of SUHI. It is noteworthy to mention that, until 2008, scientists had to pay for Landsat data and the U.S. Government has again been considering charging users for access to the Landsat archive [73]. Third, Landsat series 5, 7, and 8 capture the Earth's surface in a 16-day repeat cycle with swath coverage of $185 \mathrm{~km} \times 185 \mathrm{~km}$. The temporal resolution provides a reasonable period to reflect the changes in SUHI or land cover/use of a city and the swath coverage is big enough that it allows scientists to process a single image to investigate an entire urban environment. These both increase time efficiency and accuracy of the SUHI studies. Note that the atmospherically corrected Landsat thermal data was not previously available as a standard product, and researchers either used top-of-atmosphere temperature values or employed various methods to atmospherically correct the data themselves [39]. Currently, there is no operational Landsat LST product that combines data from the various Landsat sensors. Recently, Malakar et al. [74] developed an operational algorithm for retrieving Landsat LST consistently for all sensors. The U.S. Geological Survey and the LST dataset will implement the algorithm, which is expected to be available at the Land Processes Distributed Active Archive Center.

\subsection{MODIS}

MODIS imagery has been the second popular data source for SUHI studies (25\%). MODIS is a key instrument aboard on the Terra (1999) and Aqua (2002) satellites launched by NASA to scan the Earth's surface and atmosphere with a 36-band spectrometer and provide a global coverage every one to two days. MODIS records its images at a spatial resolution of $250 \mathrm{~m}$ (bands 1-2), $500 \mathrm{~m}$ (bands 3-7), and $1 \mathrm{~km}$ (bands 8-36). Thermal images are captured in the $1-\mathrm{km}$ resolution. Due to the spatial resolution and swath dimension of MODIS - $2330 \mathrm{~km}$ (cross track) by $10 \mathrm{~km}$ (along track at nadir)—its images are used for research of large study areas [2-6,52,75,76]. A significant benefit of MODIS is the range of quality-checked data products that are generated by the MODIS team. These data products are processed images, which can be directly used for various research purposes. Examples of such products that have been widely employed in SUHI studies include daytime and nighttime LST and emissivity data from MOD11C3, MOD11A1, and MOD11A2 [77]. The LST value in these products is retrieved by the generalized split-window algorithm [78]. In the current Collection-6 MODIS LST products, a new LST product based on the ASTER Temperature Emissivity Separation (TES) algorithm (MOD21) has also been released. It was claimed that the new data could provide increased sensitivity to a land cover change compared to other emissivity products [79]. However, the data have not been used in SUHI studies until now.

\subsection{ASTER}

In the reviewed studies, ASTER images have been the third most frequently-used data (7\%). Such a small number arises from the fact that ASTER imagery had been costly from 1999 (Launch date) 
to April 2016 even though, since then, ASTER imagery has been available to all users at no cost. ASTER collects data in 14 spectral bands and the images have spatial resolution of $15 \mathrm{~m}$ (visible and near infrared bands 1-3), $30 \mathrm{~m}$ (shortwave infrared bands 4-9), and $90 \mathrm{~m}$ (thermal infrared bands 10-14). Similar to MODIS, the ASTER team also provides a variety of products [80] such as Surface Kinetic Temperature (AST_08), which provides the LST of the Earth's surface with an accuracy of 1.5 Kelvin [81,82]. It is noteworthy that this product is available for daytime and nighttime and, thereby, provides a significant opportunity to study diurnal variation of SUHI [82]. Past researchers also derived LST from different thermal bands of ASTER for various types of SUHI studies [83-85]. However, the wide application of ASTER imagery to SUHI research was largely impeded by high cost and a limited data archive compared to other sensors like Landsat and MODIS [86]. Taking into account that ASTER data are now free, it can be expected that the use of ASTER imagery for SUHI studies will increase in the coming years. Note that almost $6 \%$ of past studies used imagery from multiple sensors to compensate for drawbacks of any given sensor's image.

\section{Methods for Measuring the SUHI}

Various methods have been developed to measure the SUHI and they, in general, can be grouped into three broad classes: LST as a proxy of SUHI, LST difference between the urban and reference areas, and non-parametric models. These three different types of methods are briefly reviewed below.

\subsection{Using LST as a Proxy of SUHI}

LST has been widely used to reflect SUHI variability, especially for local-scale studies based on Landsat series or ASTER data [66,87-107]. Such studies often concentrated on the LST variations and their relationships with spatial-temporal factors in a city [30]. The SUHI usually manifests itself in the form of hotspots [108] or higher LST of buildings/impervious surfaces than other surfaces [30]. The method can be employed to investigate the underlying driving mechanisms of SUHI at a local scale and, therefore, help urban planners formulate site-specific mitigation strategies. However, these studies usually do not estimate the intensity of SUHI, which makes comparisons of SUHIs among cities challenging.

\subsection{LST Differences between Urban and Surrounding Reference Areas}

The intensity of SUHI has been most commonly estimated by the LST difference between urban and surrounding reference areas, with the support of auxiliary land surface information, such as land cover and ISA [30]. SUHI intensity was typically quantified in two steps in those studies. First, urban and reference areas were defined and delineated from the land cover or ISA maps. Urban areas were usually referred to as the lands with a relatively higher portion of ISA $[4,6,52,76]$, whereas reference areas were defined variously by different studies. Different-sized rural $[52,53,76,109]$ and suburban $[2,4,6,62,110-115]$ zones have been used as the reference areas. Other surface cover, such as water body [116,117], cropland [117-119], forest [120], and low-intensity ISA [121] have also been taken as the references in a few studies. Second, the area-weighted mean urban-reference LST differences were calculated to reflect the SUHI intensity or magnitude. A positive value of SUHI intensity indicated an urban heating effect, while a negative value represented a sink effect. Few studies also quantified the SUHI intensity using few representative pixels in urban and reference areas instead of the area-weighted mean value for the purpose of surface-air UHI comparison [122-124] or UHI attribution analysis $[125,126]$. The urban-reference difference method facilitates the comparison analysis of SUHIs among cities, in particular the SUHI distribution at a regional or global scale, but can be limited by the large uncertainties associated with urban and reference definitions [68]. This limitation is discussed further in Section 6.4. 


\subsection{Statistical Models}

Statistical models have also been proposed to measure the SUHI by some researchers. Among these, a Gaussian surface model has been mostly utilized in previous studies [25,97,127-129] since it can provide not only the intensity but also the spatial extent and the central location of the SUHI in an area. The kernel convolution method has also been proposed to study urban heating effects because of its high efficiency in characterizing the temperature values over space in a continuous surface [130]. Recently, Li et al. [131] estimated SUHI intensity by the linear regression functions between LST and regionalized ISA. These statistical models could avoid the bias caused by the definitions of urban-rural areas or the choice of the representative pixels, and, thus, facilitate the SUHI comparisons among cities. However, they do not work in the cities partially covered by clouds and in arid cities, and, thus, have been only applied in a few SUHI studies to date.

\section{Key Research Findings}

\subsection{Understanding the Energy Basics for SUHI}

The SUHI is essentially caused by alterations of the surface energy balance after replacing natural land with an artificial surface $[1,8,9]$. The energy balance of a typical urban surface can be expressed as: incident solar radiation $\left(\mathrm{Q}_{\mathrm{I}}\right)+$ incoming longwave radiation $\left(\mathrm{Q}_{\mathrm{L} \downarrow}\right)+$ anthropogenic heat releases $\left(Q_{F}\right)=$ reflected solar radiation $\left(Q_{R}\right)+$ outgoing longwave radiation $\left(Q_{L \uparrow}\right)+$ latent heat $\left(Q_{E}\right)+$ sensible heat $\left(\mathrm{Q}_{\mathrm{H}}\right)+$ heat storage $\left(\mathrm{Q}_{\mathrm{S}}\right)$ (Figure 4). Satellite thermal sensors measure LST indirectly by detecting $\mathrm{Q}_{\mathrm{L} \uparrow}$ from the Earth surface [29]. The urban-induced SUHI, which represents an increase in $\mathrm{Q}_{\mathrm{L} \uparrow}$, and, in general, is dominated by different energy fluxes during the day and night $[1,4,6]$. The daytime SUHI is widely attributed to a reduction in reflected solar radiation and latent heat flux, which increases the sensible heat and upwelling thermal radiation received by thermal sensors [9]. In contrast, the nighttime SUHI was mainly contributed by the larger storage heat during the day for a later release at night $[2,6]$. The anthropogenic heat flux, as an urban-specific energy input, could increase the SUHI independent of the time-of-day by magnifying the upward thermal radiation and the heat storage [7]. Factors impacting any energy component of urban surface can influence the daytime and/or nighttime SUHI intensity and even convert the urban area from a source to a sink of heat.

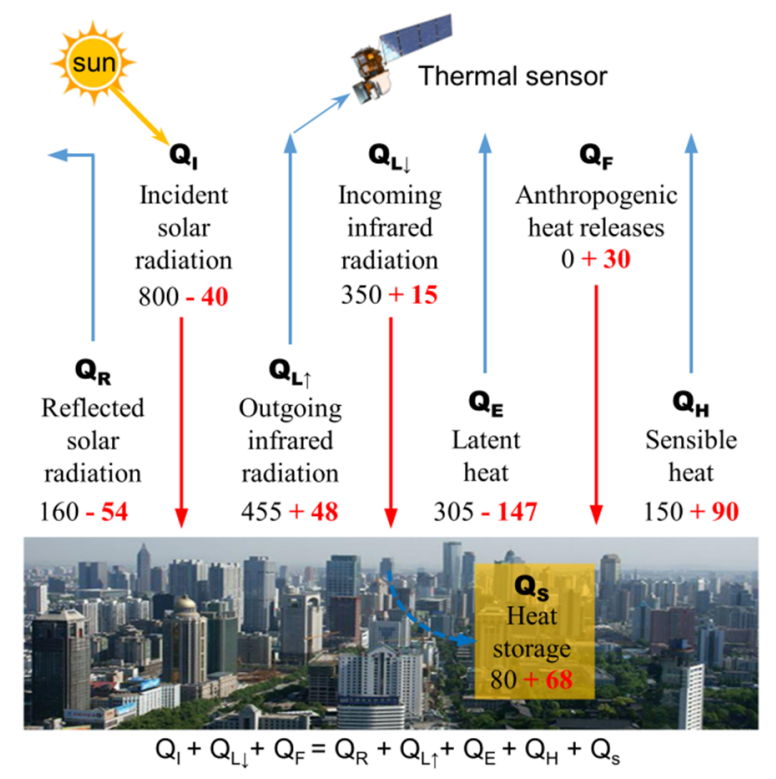

Figure 4. A diagram of the energy balance for a hypothetical urban area. Red and blue arrows designate energy input and partition in the urban system, respectively. The example values (units: $\mathrm{W} \mathrm{m}^{-2}$ ) were from Oke [132]. The values in red represent the energy change in the urban region relative to rural areas. 


\subsection{SUHI Variations at a Local Scale and Their Drivers}

Increasing studies on local-scale SUHI variations constitute the major body of SUHI literature (Figure 3c). More than 300 papers have been published and nearly $60 \%$ of these studies have appeared within the last five years. These efforts in general can be grouped into three main categories based on their studied drivers: land cover/land use and changes, urban site characteristics (USCs), and landscape composition and configuration. The USC term originally stems from Berger et al. [94] and is used here as a hypernym to summarize all kinds of quantitative descriptors helping to explain SUHI variations within cities.

Land cover/land use and their changes are inarguably some of the most important factors influencing SUHIs. Built-up areas, vegetation, and water are central to explain the spatio-temporal characteristics of urban LST [30]. The presence of buildings and impervious surfaces usually result in an increase of LST [66,95,105,106,133-135], while the opposite is true for urban vegetation $[66,81,94,95,102,105,108,116,136-140]$ and water bodies [103,106,140-143]. The impact of bare soil areas on SUHI is ambiguous, with a few studies reporting both positive [95] and negative [116] correlations with LST. Overall, land cover alone can be decisive regarding whether an urban area forms a SUHI or an urban heat sink $[30,144]$. However, the sole consideration of land cover is sometimes not sufficient for explaining the LST variations within cities. Several studies indicate that land use is a better suited parameter since it takes into account human activities $[145,146]$. For example, industrial areas are often found to be among the hottest places in urban environments due to the associated high heat emissions [62,102]. Furthermore, the degree of correlation between the land cover and LST depends on the type of urban land use [94,99,101,147,148]. However, no matter which of the two variables is actually more important, research undoubtedly shows that land cover and land use can lead to not only urban-rural temperature gradients but also intra-urban temperature differences [30]. The intra-urban differences typically manifest themselves in the form of spatial clusters of hot and cold spots [149,150], which, at times, can be even greater than the urban-rural temperature gradient [105]. Dynamics of land cover and land use over time are of equal importance in shaping the SUHI patterns. For example, urban growth can increase the SUHI extent and intensity $[95,149,151,152]$ by increasing proportions of built-up land and decreasing proportions of vegetated areas, especially in the earlier stages of urbanization [90] and/or regions undergoing rapid land cover and land use change [116].

Impacts of the three major urban land covers (built-up land, vegetated areas, and water bodies) have also been extensively studied by a wide variety of quantitative descriptors termed as USCs. The area covered by built-up land represents some of the main causes of SUHI formation [30]. Accordingly, a considerable amount of 2D indicators has been used to reflect the built-up land properties such as the ISA, the index-based built-up index (IBI), the normalized difference built-up index (NDBI), and the urbanization index (UI) $[66,94,95,99,106,133,135,138,141,143,148]$. The coverage, density, and materials of specific built-up land cover elements (e.g., buildings, roads, and parking lots) have also been related to SUHIs [82,94,153-157]. Furthermore, 3D indicators such as the building heights and volumes, the frontal area index (FAI), the floor area ratio (FAR), and the sky view factor (SVF) are regularly used to represent the effects of urban morphology on SUHI [94,102,153,156,158,159]. When comparing the linkage between 2D/3D USCs and SUHIs, it is worth noting that correlation statistics might be biased in favor of 2D USCs. This is the case when thermal infrared sensors with a nadir-pointing viewing geometry (e.g., Landsat ETM+, ASTER) are used to retrieve LST [62,94,154].

Cooling effects of vegetated areas on SUHI have also been studied in the form of various 2D and 3D USCs. The NDVI, vegetation fraction (VF), and the size of green spaces have by far received the most attention $[66,81,95,98,103,108,134,137,138,140,141,143,147,148,152,153,160,161]$. Cooling is reported to be the strongest when a city's green coverage lies between $70 \%$ and $80 \%$ [162] and the size and density of the green infrastructure is sufficient [140,143,152,160,163]. Moreover, the shape and orientation of vegetated areas matter, even though there is no consensus on whether green spaces should be of regular or irregular form [95,103,137,141]. Under certain conditions, patches of vegetation can reduce the temperatures of their surroundings by up to 24 Kelvin [30] and within a 
distance of 60 to $840 \mathrm{~m}$ [137,140,161]. Instead of analyzing all types of vegetation as a whole (i.e., trees, shrubs, and grass), many studies specifically focus on the abundance and characteristics of urban (street) trees, parks, and forests [94,98,103,135,143,164]. Among these, the percentage of tree cover is the most common used USC due to its higher potential to alleviate the SUHI than mixed vegetation $[157,165]$. Apart from the proportion of urban trees, USCs describing their height, volume, and species have also been found closely related to urban LST [30,94,137,147,164]. In addition to urban vegetation, the presence and proximity of water bodies are known to have a cooling effect on urban temperature $[62,103,106,140-142,166]$. However, impacts of the water body have been quantified by few indicators such as the normalized difference water index (NDWI) [116,167] and the distance between water bodies (or the coastline) and built-up land [142,158,165,168].

The SUHI variations have also been widely attributed to landscape composition and configuration metrics at a local scale [81,82,98,101,102,145,146,155,157,163,166,169-172]. Some authors even state that the patterns of built-up land and vegetation have the largest impact on urban LST [115]. It is frequently questioned whether landscape composition or configuration is more important. The answer to this question depends on the city under investigation [173], the land cover/land use, and the types of green space within the study area $[99,101,172,174]$ as well as the landscape metrics considered [171]. In general, composition is often found to be more important than configuration $[95,103,157,163,169,170,175]$. This is particularly true when landscape metrics describing composition and configuration are compared on an individual basis. However, when feeding several metrics into a regression model to estimate LST, the combination of certain measures of landscape configuration outperforms all other predictor sets [171,175]. In the same context, Du et al. [171] also noted that the joint usage of multi-scale metrics (i.e., patch-level, class-level, and landscape-level metrics) takes into account the hierarchical structure of urban landscapes, and, thus, can improve LST modeling. It is, therefore, not without reason that a few studies suggest to choose one composition metric and a small selection of configuration metrics to investigate SUHI variations $[169,175,176]$.

\subsection{SUHI Variations among Cities and Their Drivers}

SUHI variations among cities had been a research focus since the beginning of the SUHI research when the satellite data were only available at a coarse spatial resolution $[33,55,57]$. However, local-scale SUHI studies soon dominated the SUHI literature and this has continued to the present with the advent of high-resolution satellite data like Landsat and ASTER. As a result, there were very few studies on large-scale SUHI variations before 2010. With advancing quality and quantity of remote sensing data (in particular MODIS data) as well as increased computing power, more researchers started to look at the SUHI phenomenon on a regional scale [114,120,139,177-179], a national scale like China [6,53,75,76,109,115,121,126,180], the United States [3,52], and India [181,182], a continental scale such as Europe [5,68,111,183], North America [125], and Asia [127], or a global scale $[2,4,50,65,184]$. These studies have greatly enhanced our knowledge on large-scale SUHI variations and their underlying potential drivers.

The previous efforts indicated a great deal of spatiotemporal variability of SUHIs, especially during the daytime. SUHI intensity has been widely found to be the largest during the day in the summertime with the maximum urban-rural LST difference $>10$ Kelvin $[4,6,52,53,76,112,127]$. In general, the daytime SUHI was larger in humid-hot cities than in their cold-drier counterparts, and larger in the summer than in the winter $[4,6,52,53,76,112]$. In contrast, cooling effects have been found in some arid cities during the summer season [52,181,185] and a few mid-high latitudinal cities in the winter season $[6,76]$. Comparatively, SUHIs have been observed to be more pervasive at night regardless of the background climate and/or season [6,76,181,182]. However, the mean SUHI intensity was mostly estimated to be lower at night than during the day, especially in the summer $[4,6,52]$. In addition, stronger nighttime SUHIs were often found in cold-drier cities than humid-hotter cities [53,76,112]. In addition, seasonal variations of SUHIs were clearly smaller at night than in the day [53], and the nighttime seasonal patterns remain controversial to date. For example, 
Peng et al. [76] suggested more intensive nighttime SUHI in the summertime than in the wintertime for 285 cities in China. Zhou et al. [6,53] showed opposite trends for 32 major cities in China.

SUHI distributions had been attributed to a variety of factors (Figure 5) and some of them are still highly disputed. The climate-vegetation background was found to be the main cause of the spatiotemporal variability of SUHI over large areas $[6,52,53,125]$. Vegetation, which cooled the non-urban surface by evapotranspiration, was widely documented as a dominant factor in regulating the SUHI patterns during the summer $[2,4,6,50,51,53,139,182,185]$. Overall, it contributed little to SUHI variations in the winter due to low vegetation activity for most cities in the season $[4,6]$. However, it remains controversial whether vegetation contributes significantly to the SUHIs during summer nights $[4,6,109,186]$. Background climatic factors such as precipitation $[6,53,125,178]$, temperature [6,109,111,114,178], wind speed [178], and solar irradiance [139] can significantly influence SUHIs since they can impact not only vegetation activity but also the energy balance of urban and rural areas $[6,125]$. In fact, the climate was usually considered the ultimate factor that shapes the spatiotemporal patterns of SUHIs over large areas $[6,52,53,125]$.

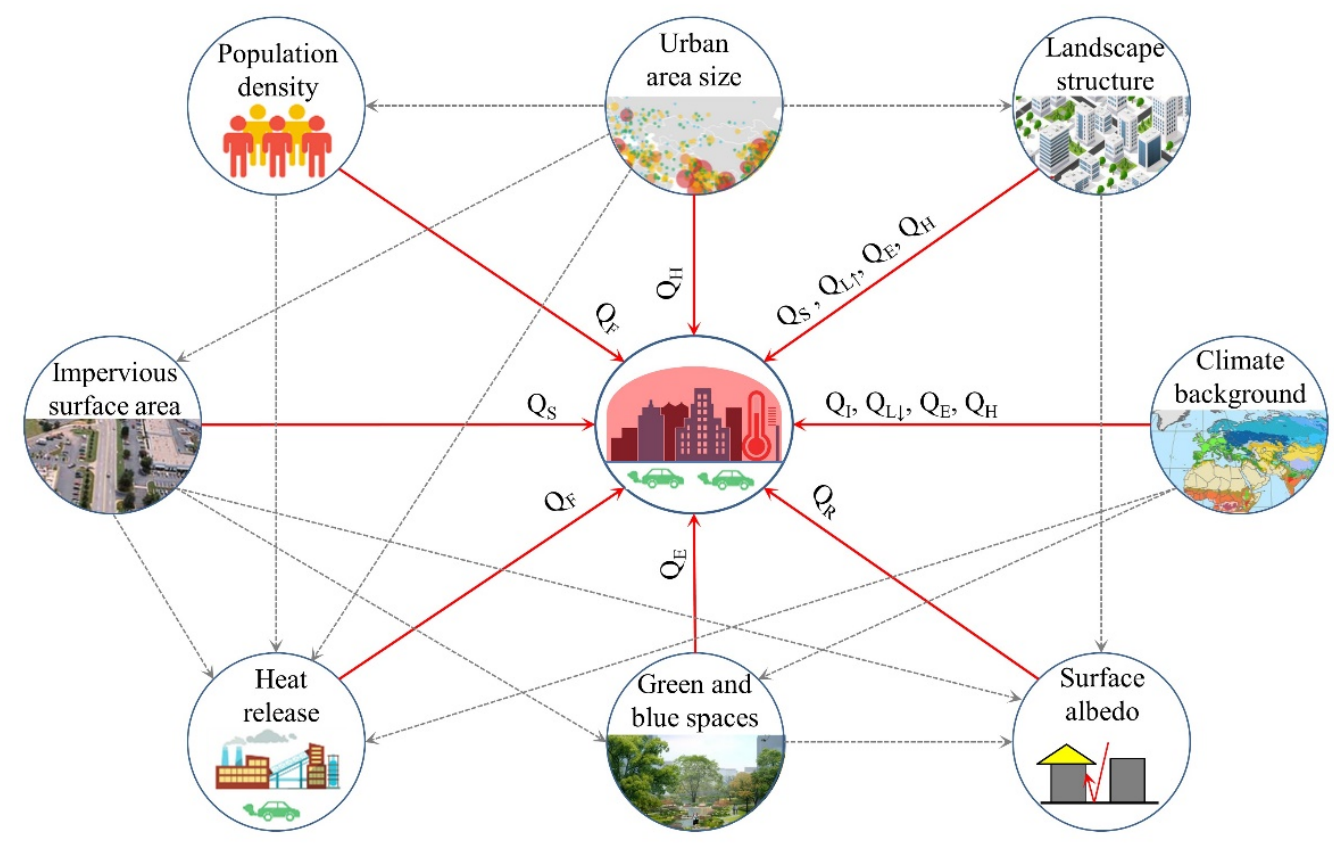

Figure 5. Potential impacts of the studied factors on SUHI's variability among cities. The red solid and gray dashed arrows represent the direct and indirect effects, respectively. Energy components influenced by these factors directly were listed above the arrows.

Anthropogenic factors also contribute significantly to SUHI distributions. ISA, warming urban surface by trapping, storing, and emitting more heat, is positively correlated with SUHI in the summer and/or nighttime $[2,6,177,180,183]$, and was shown to be the primary driver for urban heating effects at mid-latitudes to high-latitudes [50,52]. For example, Zhang et al. [50] showed that ISA explained more than $60 \%$ of the total LST variance for cities surrounded by forests at mid-high latitudes. However, a recent study by Zhou et al. [120] found an insignificant correlation between SUHI and ISA in a highly populated urban agglomeration area. Urban area size was also found positively and significantly related to SUHI $[2,5,52,177,178,184]$ and even to be a dominant factor of SUHI $[3,50]$. For example, Li et al. [3] demonstrated that nearly $87 \%$ of the SUHI variations among cities in the United States could be explained by the urban area size, especially in the regions with relatively homogeneous land covers surrounding urban areas. At the same time, some studies have indicated a minor or insignificant effect of urban area size on SUHI $[4,6,139]$.

Similarly, both significant positive $[114,120,127,184,187]$ and insignificant $[2,4,178,179]$ correlations have been found between SUHI and the urban population. Some studies have stressed the importance 
of the urban landscape structure $[5,115,177]$, while others showed that it made a weak contribution to SUHI variations among cities [2,184]. Other factors such as surface albedo $[4,6,51,65,125]$, energy consumption or anthropogenic heat release $[4,6,75,112,178]$, and atmospheric aerosols $[126,181]$ have been suggested as major drivers for SUHIs. The contrasting data sources, methods, geographic regions, scales, and periods of past SUHI research caused these diverse and/or controversial results. This is discussed below in Sections 6 and 7.

\subsection{Relationship between Surface and Air UHIs}

Since air UHIs are commonly impeded by lacking sufficient spatial detail for urban land use planning [25-28], predicting the air temperature in both urban and rural areas indirectly from satellite observations has gained considerable interest [25,32,188-191]. Finding a simple and general relationship between SUHIs and air UHIs is not an easy task and the published relationships remain empirical [29]. Generally, the largest air UHI intensity is observed at night, while the SUHI peaks during daytime [62]. Air UHIs are often weak during the late morning and throughout the daytime and become more pronounced after sunset, due to the slow heat release from urban structures.

Surface and air UHI differences and the timing of their peaks depend on the urban and rural surface properties (e.g., moisture, aerodynamic roughness, albedo, emissivity, and thermal admittance), season, geography, and prevailing weather conditions [29,192]. Schwarz et al. [20] carried out a campaign in Leipzig, Germany, providing LST from airborne flights and air temperature $\left(\mathrm{T}_{\text {air }}\right)$ from weather stations and a mobile traverse. A higher SUHI magnitude was detected in the morning than in the evening, whereas the diurnal trend was opposite for the canopy layer heat island (CLHI) [20]. Zhang et al. [193] examined 48 cloudless, anti-cyclonic nights in Birmingham, UK, from 2002 to 2007 by using MODIS LST and $\mathrm{T}_{\text {air }}$ from ground stations. The nighttime SUHI-CLHI comparison revealed a linear relationship, whose slope was partially explained by the built-up area fraction inside the satellite pixels [193]. For the city of Milan, Italy, surface UHIs, retrieved from 403 MODIS summer images available four times a day from 2007 to 2010, highlighted how the SUHI has a diurnal cycle, with the highest intensity in the early afternoon. This is halved during the night. By contrast, the CLHI is absent during the daytime and emerges after sunset showing features similar to the nighttime SUHI [25]. The same daytime/nighttime behavior was found by computing SUHI from MODIS and CLHI from meteorological stations across 300 urban areas in the United States [124]. Surface and air UHIs retrieved from a year of MODIS data over Beijing, China, showed agreement during the night regardless of the season, but an evident difference during the daytime, with the SUHI-CLHI intensity difference being small and negative during the cold months while being large and positive during the warm months [189]. Azevedo et al. [194], using $\mathrm{T}_{\text {air }}$ from a meteorological network and MODIS LST during the summer months in 2013 in Birmingham, UK, demonstrated that SUHI is clearly linked to land use, whereas CLHI is more influenced by advective processes that cause different spatial patterns. Surface and air UHIs exhibited exponential decay trends moving away from the urban area of Wuhan, China, with different magnitudes. This was more evident in the summer than in the winter [195]. In the region of Hangzhou, China, the UHIs computed by $\mathrm{T}_{\text {air }}$ from weather stations and LST from Landsat images were not comparable, which demonstrates the importance of the choice of dataset, acquisition time, and weather conditions for SUHI-CLHI comparison [196].

\section{Research Challenges}

Despite the unparalleled advantages of satellite images to explore the SUHI, researchers confront a series of difficulties in using them due to both data and methodological limitations. The main research challenges are summarized below.

\subsection{Differences between Satellite-Derived LST and Air Temperatures}

Remotely-sensed LST is completely different from air temperature in terms of observation principles and altitudes, which makes SUHI not directly comparable to air UHI [29]. Thermal sensors 
measure surface temperature indirectly by detecting upward long-wave radiation from the Earth surface at a narrow solid angle of view (Figure 6). Thermodynamic and radiative properties, including surface energy input from the atmosphere and sun, surface moisture, and thermal admittance, surface emissivity, near-surface atmospheric conditions, and surface turbulent transfer can seriously affect the upwelling surface radiation [197]. The radiances received by remote sensors are further influenced by the sensor-viewing angle [29]. A large fraction of the urban surface may not be viewed by sensors because of the three-dimensional nature of the urban structure obscuring some of the surface from view, and the atmosphere may absorb a significant portion of the radiation [24]. At the same time, some atmospheric radiation may be received by sensors directly without interacting with the Earth surface or the target objects (Figure 6). The accuracy of LST estimates, therefore, depends strongly on corrections for atmospheric effects and an accurate estimate of surface emissivity [28,35,54,198]. These two, however, are often difficult to assess given large areas covered by remotely sensed imagery and the lack of detailed atmospheric parameters at the time of satellite overpass [38]. For example, surface emissivity was usually assumed to be the same across a heterogeneous urban area [35]. Furthermore, the interpretation of satellite-derived LST data is hampered because urban pixels are generally not homogeneous and isothermal. They usually include several active surfaces that have different thermodynamic and radiative properties and, thus, different temperatures. In addition to the internal errors of sensors and cosmic background noise, the pixel-based LST estimate is an ambiguous quantity found by inverting Planck's law.

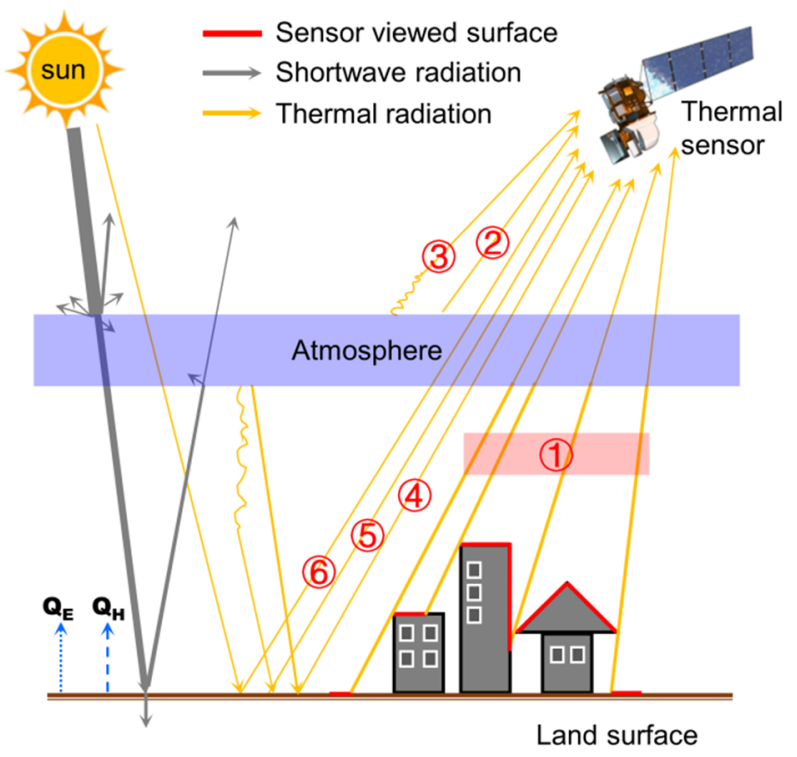

Figure 6. Illustration of the infrared radiance received by a satellite sensor. Path (1): radiance emitted directly by the target surface. Path (2): upward atmospheric thermal radiance. Path (3): upward solar diffusion radiance scattered by the atmosphere. Paths (4): downward atmospheric thermal radiance. Path (5): downward solar diffusion radiance. Path (6): direct solar radiance reflected by the surface. The radiance from paths (1), (4), (5), and (6) will be attenuated by the atmosphere before reaching the sensor. Among these channels, only the radiance from path (1) is directly related to land surface temperature and the emissivity of interest. The solar-related items (paths (3), (5), and (6) are usually ignored in LST retrieval due to a negligible solar radiation infrared thermal window of 8 to $14 \mu \mathrm{m}$ and 3 to $5 \mu \mathrm{m}$. Further details can be found in a review article by Li et al. [38].

Therefore, a considerable gap exists between the retrieved LST and air temperature, on which turbulence and wind have a significant effect [24]. Given the closer relationship of air temperature with the urban environment and human health than LST [31,32], various sensor-view models have been proposed to predict air temperature from LST data [199]. However, model performance needs to be examined, because of the highly complex interrelationships between surface and air temperatures. 
It remains a grand challenge to apply the satellite-derived LSTs directly in air UHI detection, attribution, and modeling [28].

\subsection{Impacts of Clouds and Other Factors on LST Data}

Satellite-derived LST data are severely affected by clouds and other factors such as scene view angles and internal errors of sensors [24,200]. White-Newsome et al. [201] reported that, among 21 images they browsed for the study in Detroit, US, only one image was cloud-free. Hu et al. [69] found that there were significant thermal anisotropies in urban areas and the effects could be up to $9 \mathrm{~K}$. To improve the accuracy of LST products, cloud-contaminated pixels are often removed by cloud-screening algorithms [202]. However, scene view angles and anisotropic effects have been overwhelmingly ignored in SUHI studies [203]. As a result, missing or low-quality pixels are not uncommon in LST products, especially over urban areas [204]. For example, Li et al. [205] found that the MODIS daily LST product generally covered less than $30 \%$ of the urban areas in the conterminous United States. The issue of missing pixels largely limits the application of LST in investigating the SUHI, which has significant spatial and temporal variations.

Temporal aggregation has been widely used to build a cloud-free and seamless remote sensing product. For instance, daily LST data can be aggregated to a coarser temporal resolution, such as 8-day and monthly composites. However, temporal variation of LST is reduced in the derived product, which results in the loss of temporal information of SUHI. The derived data may not be able to distinguish extreme events, such as heat waves, which are one of the most important issues in urban climate studies [206]. Additionally, such methods have been widely criticized for their associated accuracy losses [203,207-210]. Hu and Brunsell [207] suggested that temporal aggregation of LST increased the SUHI values substantially, especially during the daytime, in the summer, and in high SUHI regions, with higher biases in larger composite periods. Gawuc and Struzewska [203] and Lai et al. [209] confirmed that quality control can significantly impact the SUHI estimates either by removing poor-quality pixels or weighting the pixels according to their quality, especially in urban centers.

Therefore, it will be important for SUHI studies to fill gaps in LST data and develop a seamless daily LST product. New methods have been proposed for such a purpose in previous studies [211], such as integrating multi-source datasets from different sensors [212-215], daily merging using statistical relationships between observations at different overpass times [216], empirical relationships using auxiliary data (e.g., land cover and NDVI) [217], and geostatistic-based spatial-temporal interpolation $[218,219]$. These methods have been used individually or jointly to generate seamless LST products. For example, Crosson et al. [216] developed a daily merged MODIS Aqua-Terra LST dataset for the continental United States. Li et al. [205] developed a seamless LST product for urban areas in the continental United States by combining daily merge and spatial-temporal interpolation. However, there are challenges of efficiency and accuracy in these methods [211]. Large computing resources are needed in some of these methods, especially for large areas, while the uncertainties in the resulting LST products from other methods are large. Most importantly, the gaps in LST (e.g., cloud-contaminated pixels) are usually filled by the clear-sky observations, which may be higher than the actual LSTs under cloudy sky conditions [205,220]. In other words, SUHI estimates based solely on clear-sky LST values would overestimate the SUHI effect no matter whether gaps were filled or not. Recently, a few studies have successfully generated all-weather LST values by fusing MODIS and passive microwave data (AMSR-E) [221,222]. However, the coarse spatial resolution of AMSR-E $(\sim 25 \mathrm{~km})$ impedes its application in urban areas. In addition, even though the cloudy pixels have been removed, cloud effects on the adjacent non-cloud pixels still exist and will impact LST interpolation and downscaling methods [207]. New developments for improved approaches or the trade-off between efficiency and accuracy of the existing methods is still needed. 


\subsection{Trade-Off Between Spatial and Temporal Resolutions}

A trade-off between spatial and temporal resolution is nearly always present in SUHI research due to technique limitations. Some sensors like Landsat series and ASTER can yield LST at a relatively high spatial resolution (60-120 m), but are restricted by the lack of data for the nighttime period and low temporal resolution. High-temporal resolution sensors such as AVHRR and MODIS can only provide LST at a medium or coarse resolution $(\geq 1 \mathrm{~km})$. The choice of the image was often determined with a research focus [223]. For example, high-spatial resolution images were preferred for understanding the SUHI variations within a city and, thus, provide insights for local city planners. In contrast, high-temporal resolution data were required to calculate energy parameters or to examine the relationships between SUHI and bioclimatic factors (e.g., air pollution).

However, the current satellite-borne sensors can never entirely meet the needs of scientific research and practitioners because of the high spatio-temporal variability of the SUHI phenomenon [108,224,225]. Sensors with a 50 to $100 \mathrm{~m}$ pixel size have been proven to be most suitable in urban thermal environment studies [39,226,227], which means that the resolution of the most widely used sensors known as Landsat TM/ETM+/TIRS is close to the optimal spatial resolution. However, they are commonly impeded by limited thermal calibration, no nighttime data, and a long revisiting cycle.

In addition, remote sensing satellites orbit the Earth in a sun-synchronous orbit and, thereby, show a region at a constant specific time of a day/night known as the local sun time. However, SUHI experiences great variations during the day/night. Chudnovsky et al. [228] showed that a SUHI study should cover the two times of day: early noon hours (12:00-13:00 p.m.) and early morning hours before sunrise (5:00 a.m.). However, satellite images are likely not available at these specific times. Geostationary satellites like GOES and SEVERI sensors serve as the ideal platforms for understanding diurnal cycles of SUHI, but their coarse spatial resolution, limited coverage area, and low accuracy have impeded their wide application in SUHI studies [129].

Some spatial downscaling and temporal upscaling algorithms have been proposed to increase the spatial [223,227,229,230] and temporal [208,210,231] resolutions of LST data, respectively. Those methods have revealed a wealth of information that can partially compensate for the resolution problems, but at the cost of accuracy [223]. Therefore, new satellite missions focusing on reducing pixel size and increasing temporal frequency should be the most fundamental way to promote SUHI research and practice. Besides the upcoming large satellite missions such as Landsat 9, increasing "small satellites" with high spatial, temporal, and spectral resolutions may provide valuable data sources for local or regional SUHI studies in the future [232].

\subsection{Methods to Calculate SUHI Intensity}

While various methods have been used to quantify SUHI, it is challenging to compare SUHIs across cities or studies due to the highly diverse SUHI estimates. For example, Schwarz et al. [68] compared 11 methods for quantifying SUHI in 263 European cities and found weak and even negative correlations between the calculated SUHI intensities in most cases, especially during the daytime. Yao et al. [233] indicated that the SUHI value averaged for 31 Chinese cities differed by a factor of two among the five commonly used methods. Zhou et al. [234] showed that different methods would lead not only to contrasting intensities but also to opposite signs (from a heat island to a cool island) of the SUHI estimates, particularly in arid cities and during the daytime. 
The varying results from different methods can be attributed primarily to the large uncertainties associated with the definitions of urban and reference areas [235]. For example, the SUHI intensity would most likely be underestimated if referenced to nearby suburban areas, since the SUHI footprint usually extends far beyond the physical boundaries of urban areas [234]. The SUHI intensity, defined as the urban-rural LST difference, also varied considerably across cities and studies due to the strong control of agricultural activities (e.g., irrigation) on rural LST [186]. In highly urbanized metropolitan areas, nearby reference areas will very likely be influenced by the SUHI of neighboring cities [120]. Some methods such as the linear regression slope of LST with regionalized ISA [131] and the LST difference relative to natural vegetation condition [120] have been developed to avoid the bias caused by urban-rural definitions, but they are largely limited by data quality [131] or the natural vegetation coverage [120].

\subsection{Concurrent Land Cover and Use Mapping}

Rapid changes in land cover, especially urban extents, have been overwhelmingly ignored in large-scale SUHI studies, since it remains a challenge to obtain regional or global land cover data at an annual or timely manner [236]. As a result, most previous studies used outdated urban area maps $[4,52,111]$ or a limited number of urban maps $[6,53,109,234]$ to characterize the SUHI intensity over a long time period. For example, Peng et al. [4] studied global SUHI distribution using LST data between 2003 and 2008, but they used the land cover in 2000. Zhou et al. [53] estimated the SUHI intensity from 2008 to 2012 in 32 major Chinese cities using the land cover data in 2010. Zhao et al. (2016) reported that the SUHI intensity might be underestimated by $50 \%$ by using outdated urban-extent maps in China, especially during the daytime. This calls for an accurate and concurrent mapping of land cover that can appropriately characterize the changes in land cover in estimating SUHI intensity and its change over time, in particular for the rapidly urbanizing areas like cities in China and India [18]. For example, efforts such as global urban dynamics mapping that contributes to SUHI studies, especially over large areas, are encouraged [237].

\subsection{Accuracy Assessment}

Assessment of the accuracy of the satellite-derived LST and SUHI intensity is challenging and rare. Generally, LST can be verified by the temperature-based (T-based), radiance-based (R-based), and inter-comparison methods, but they all have limitations $[39,202,238]$. The T-based method, depending on in-situ LST measurements, is usually restricted to homogeneous surfaces (i.e., rural areas) in order to increase the representativeness of the observations at the satellite pixel scale. The R-based method, which relies on the simulated radiances at the top of the atmosphere, is largely limited by the accuracy of the model inputs, including land surface emissivity and in-situ atmospheric profiles. The inter-comparison method, which is based on other well-validated LST data, is strongly influenced by varying spatial scales, acquisition times, and viewing angles between sensors. Further details on LST validation can be found in a recent review by Mohamed et al. [39]. As a result, most of the SUHI studies did not report the accuracy of the retrieved LST, especially those using Landsat and ASTER data. Validation of SUHI estimates is more limited because of the lack of the urban-rural paired in-situ observations synchronized with image acquisition. Fortunately, a few validation studies suggested a relatively high accuracy of satellite-derived LST (relative error $<5 \%$ ) and its capability in characterizing an urban thermal environment $[202,224,239,240]$. In addition, all the studies used the standard satellite products and the commonly-used LST retrieval algorithms. These together solidify the reliability of previous research findings on SUHI.

\subsection{Methods to Attribute SUHI}

Attributing SUHI is also challenging in SUHI research. Spatial-statistical methods such as the ordinary least squares regression [171], comparative analysis [133], and geographically weighted regression [241] have been used to examine the potential drivers of the SUHI. The statistical 
relationships, on one hand, depend strongly on variables chosen, study scales, research time, and/or data availability. For example, Imhoff et al. [52] attributed the SUHI variations across cities in the continental United States to the ecological context. Peng et al. [4] emphasized the role of vegetation and surface albedo in driving global SUHI distributions during the daytime and nighttime, respectively. Zhou et al. [53] stressed the climate-vegetation control on the diurnal and seasonal cycles of SUHI in mainland China. Local-scale SUHI variations have been widely attributed to two-dimensional land surface properties such as ISA, NDVI, water body, surface material, population density, and landscape structure [30]. Contributions of the three-dimensional features of buildings [94], climatic conditions [126], and anthropogenic heat emissions [242], however, have been rarely investigated due to data limitations. In addition, there are strong interactions and serious multi-collinearity problems among different variables (Figure 5) [6]. For instance, a higher ISA was nearly always accompanied by a larger population density and lower vegetation activity at a local scale. The independent and combined effects of different drivers as well as their underlying mechanisms remain poorly understood. As a consequence, contributions of some factors such as the urban area size, population, and landscape structure remain highly disputed (see Section 5.3).

\subsection{Methodological Problems and Recommendation}

Uncertainties associated with the previously mentioned challenges have been further exacerbated by the methods widely used in the currently available SUHI publications [43]. The major issue is the analysis of limited data. For example, approximately $64 \%$ of the publications used a single-time-point data to represent the SUHI effect in a season or year. These publications focused on local-scale variability of SUHI based on Landsat and/or ASTER data. The fact is that the LST/SUHI values vary constantly and substantially by time due to changing climate/weather conditions, vegetation activities, and human activities [53,119]. Using a single or a limited number of LST images may be misleading especially for those studies concentrating on the temporal changes of SUHI. In addition, some studies retrieved the LST from the top-of-atmosphere radiances by employing only the emissivity correction $[91,93,133,243,244]$. As stressed in Section 6.1, both atmospheric and emissivity corrections are key for an accurate estimation of LST. Given the free availability of long-term archived data, the use of a large number of images or a time-series-analysis is greatly recommended in future studies [215,245]. In addition, reviewers of scientific manuscripts should ensure that these studies use sufficient data and perform the necessary atmospheric corrections for the interpretations made.

\section{Future Directions}

\subsection{More Attention to the Understudied Regions or Cities}

Given the large geographic biases of past literature (Figure 2), there is a clear need for more SUHI research in Africa, South America, and India due to their high urbanization potentials and/or climate sensitivity. Urban population growth (Figure 7) and land expansion are projected to occur mainly in Africa and Asia in this century, especially in Nigeria [17,18]. At the same time, Africa constitutes one of the most vulnerable areas to climate change impacts, particularly to heat stress effects due to resource scarcity [246]. South America, while less populated (Figure 7), is also very vulnerable to climate change because of its high level of poverty [246]. India, as the second most populous country, is expected to experience the largest population growth in the near future worldwide [17]. However, SUHI research in India remains scarce compared with that in China and the United States (Figure 2). 


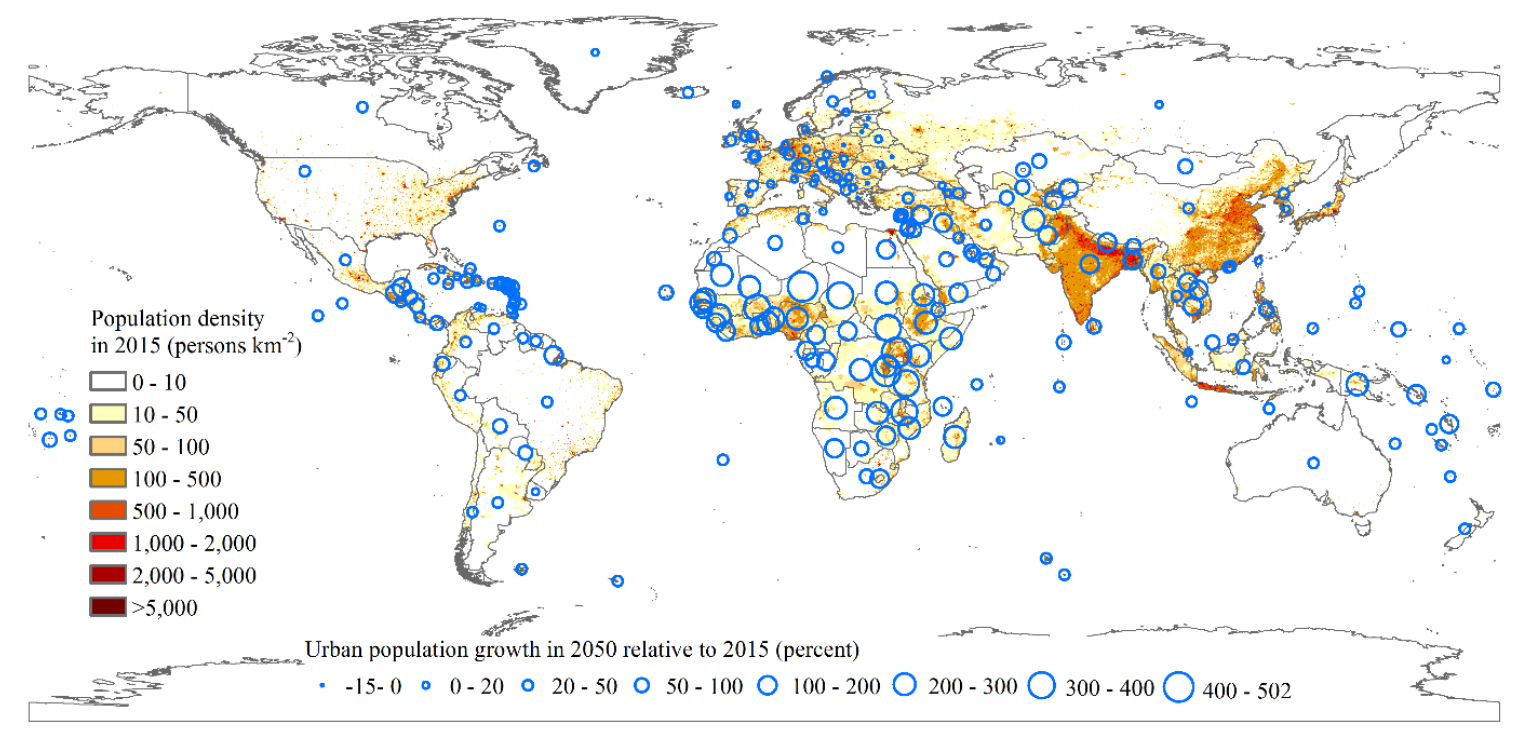

Figure 7. Global distribution of population density in 2015 [247] and the projected urban population growth in 2050 relative to 2015 in each country [17].

In addition, medium-small sized cities ( $<1$ million urban population) should be the focus of more studies since they house approximately $59 \%$ of the world's urban dwellers [17] and might also experience a strong urban heating effect [120,139]. For example, Li et al. [3] and Zhou et al. [5] investigated the SUHIs in all the cities larger than $10 \mathrm{~km}^{2}$ in the United States and Europe, respectively. They both indicated obvious SUHI in the majority of cities and a logarithmic upward trend of SUHI with a larger urban area size. Heinl et al. [139] found significant SUHIs even for cities less than $1 \mathrm{~km}^{2}$ in South Tyrol. Zhou et al. [120] reported that the largest SUHI intensity did not happen, as anticipated, in the large cities of a highly populated urban agglomeration area in east China. This is due to the stronger control of the local background climate on the SUHI variance among cities when compared to urban size. Unfortunately, the vast majority of previous SUHI studies concentrated on large cities, presuming no SUHI or weak SUHI in small cities. Therefore, more SUHI research should be directed to medium-small cities, where urban areas are expanding more rapidly than large counterparts in terms of the rate [248] and knowledge regarding SUHI, which is currently lacking [3].

\subsection{New Methods to Quantify SUHI Intensity}

As summarized in Sections 4 and 6.6, SUHI intensity may vary greatly due to differences in the selected urban/reference areas. A classification to distinguish between different urban surface components can help the selection of urban/reference areas to quantify SUHI. Stewart and Oke [235] developed a new method of local climate zone (LCZ) to establish an urban landscape classification system. A LCZ refers to an area with uniform urban land use, morphology, material, and metabolism, and demonstrates a characteristic air temperature regime at screen height. This LCZ provides a reference system for the selection of urban/reference areas to calculate SUHI intensity. This method has been validated for the purposes of urban landscape classification in both surface and air UHI studies [249]. At present, LCZ maps have been widely developed in numerous cities (http:/ /www. wudapt.org/cities). However, the LCZ method requires a large number of input datasets including some that are not easy to obtain globally. Additionally, the derived SUHI intensity based on the LCZ map still only represents inter-zone temperature differences. There remains a large uncertainty associated with the selection of urban-rural reference zones [235].

With the development of new urban datasets and spatial analysis methods, more universal methods have been proposed for the calculation of SUHI intensity, with the possibility to ease the challenges to delineate the extent of urban/reference context. For example, a consistent method has 
been proposed to determine urban and reference areas, which defines the surrounding buffer as having the same size as the urban area, by using nighttime light or land cover data $[3,4,6]$. SUHI intensity was also quantified based on the relationship between LST and urban indicators, such as urban fraction and ISA [131,250]. The relationship between SUHI and urban size can potentially be used to quantify SUHI intensity because SUHI intensity usually increases with the expansion of the urban extent [5]. Bonafoni and Keeratikasikorn [251] investigated the relationship between the spatial trend of LST and the distance to the city center using a ring-based buffer approach. They found that the daytime LST can be modeled using an inverse S-shape function, whereas the night-time LST can be modeled using a quadratic function in Bangkok, Thailand. The fitted LST functions against the distance that provides a potential way to quantify SUHI intensity. Compared with the traditional methods, these new methods consider more urban information (e.g., urban land cover and expansion) and can better represent the overall characteristic of SUHI. The uncertainties due to the selection of urban/reference areas in previous methods can be mitigated to a large extent. Therefore, the SUHI intensity calculated using these new approaches can be more reliable and more comparable to one another.

\subsection{Interannual Variability and Long-Term Trends of SUHI}

The spatial, diurnal, and seasonal variations of the SUHI have been extensively studied, but the inter-annual variability and long-term trends remain poorly understood primarily due to data limitations. The AVHRR sensor provides the longest record at a high temporal resolution, but it was utilized to analyze the SUHI in the early literature because of its coarse spatial resolution and low data quality [30,62]. The Landsat archive has provided LST observations for more than 30 years at a high spatial resolution, but the long revisiting cycle impedes the wide application in detecting the SUHI's inter-annual variability of SUHI $[119,213]$. As a result, the previous efforts focused mainly on the impacts of urban expansion on LST using the data in a few representative years and days of the year [88,90,252-255]. The increasing duration of the MODIS LST record, with high temporal resolution and data quality, allow us to examine both inter-annual variability and long-term trends of SUHI after 2000. However, such efforts have been restricted to a few regions like China [76,109,121], India [256], Mediterranean [179], and Thailand [257] due to the relatively short observation time and coarse spatial resolution. An integrated use of multi-source data (e.g., MODIS and Landsat) could generate LST observations at both high spatial and temporal resolutions, but the cost of accuracy [215,258]. It is foreseeable that the inter-annual variability and long-term trends of the SUHI will attract rising interests from researchers when more data and new data fusion techniques become available.

\subsection{Scale Issues of SUHI}

The variety of scales and their potential impact on study findings have generated a challenging dilemma for researchers to "determine the most appropriate scale and resolution of studying and assessing the effects of scale and resolution" [259]. This certainly applies to SUHI studies in which scientists inherently engage with all the scales from a UHI perspective and from LST data used to measure the associated SUHI. On one hand, UHI is formed by multiple processes on a small scale such as human metabolism to meso-scale phenomena like synoptic weather patterns [24]. The significance of a process depends strongly on the resolution of observation. Nevertheless, there is no feasible way to consider all-scale processes simultaneously due to data and knowledge limitations in characterizing the phenomenon at each scale. On the other hand, LST data vary greatly by sensors in terms of spatial and temporal resolutions, which suggests that SUHI results might be sensitive to the sensor choice. Some studies proved the scaling effects of SUHI formulation in terms of spatial extent and pixel size [171,173,225,260-263], but they concentrated mainly on the relationship between SUHI and land surface properties (e.g., landscape features, ISA, and NDVI) at a local scale. Several key scale issues remain unclear. For example, what are the differences in the factors contributing to the SUHI at local, regional, and global scales? Are there predictable differences in the magnitudes and patterns of SUHI derived from the LST observation at different spatial and temporal resolutions? What is the extent of a 
metro city SUHI impact on the climate or SUHI of associated satellite cities? What is the optimal scale for conducting measures to mitigate SUHI? The previously mentioned discussion suggests caution with regard to the scale of study when interpreting the previous results, and thus warrants a significant need for a thorough investigation of SUHI from a scale perspective.

\subsection{Relationship with Subsurface Temperature}

While many efforts have been devoted to the study of surface and air UHIs, little research has been done in terms of the detection and understanding of the subsurface urban heat island (SubUHI). Although UHI effects mostly originate near the ground surface, the resulting urban heat fluxes will propagate both upward into the atmosphere and downward into the subsurface [264]. Analysis of the SubUHI pattern is also useful for understanding the UHI dynamic across the entire vertical profile (i.e., from the atmospheric boundary layer to subsurface) [265]. The SubUHI is less studied and poorly understood mostly because of the lack of measurements provided by a suitable observation sensor network. Typically, the subsurface temperature (SubST) is driven by the heat flow from the Earth's interior and by the ground surface temperature [264,266]. Huang et al. [266] analyzed surface air temperature and borehole SubST records from a ground sensor campaign in Osaka, Japan. They found that air temperature heating is not as strong as the subsurface warming. Using two SubST observation stations in an urban and a rural area of Nanjing, China, a previous study showed that SubUHI intensity generally increased with increasing ground depth [267]. The analysis of temperature observations from a sensor network in shallow aquifers beneath six German cities showed that the derived SubUHI exhibited a more pronounced intensity with respect to the annual air UHI pattern [268]. The first attempt to detect the SubUHI by satellite remote sensing was described in Zhan et al. [265], where a three-time-scale model, able to produce SubST up to a depth of around $10 \mathrm{~m}$, was applied to MODIS data. In this study, a comparison between SUHI and SubUHI was performed in Beijing, China, which showed that the land cover changes from natural to built-up surfaces have an impact on both LST and SubST. In addition, the time delay between SUHI and SubUHI in reaching the extreme intensities depends on the depth difference. Therefore, the use of satellite remote sensing for the simultaneous detection and analysis of surface and subsurface UHI patterns is a challenging opportunity that may become increasingly widespread in the future, through validation and calibration campaigns aimed to assess the reliability of satellite-derived SubST.

\subsection{Integration of Remote Sensing with Field Observation and Numeric Modeling}

Despite their advantages, remote sensing techniques for detecting SUHI wall-to-wall at multiple scales have clear shortcomings. Satellite-derived SUHI are not only different from air UHI, but also strongly influenced by the spatial-temporal resolutions of the data, satellite overpass time, and weather conditions [29,30,269]. Comparatively, direct observations can provide time-continuous and all-sky measurements of air UHI [8], while numerical modeling can help predict and attribute surface and air UHIs at a temporally and spatially seamless manner [24]. A combined use of these three techniques can certainly provide a more thorough picture of an urban thermal environment [30,125]. For example, we can use remote sensing data and field observations to parameterize, improve, and/or evaluate numeric models. An improved model can then be used to simulate and predict UHI based on various urban growth scenarios. These UHI projections are crucial for decision-makers to formulate the urban growth policies that aim to minimize the possible negative impacts of the UHI effect. However, such studies are very limited [270-272] because (1) there are large spatial (vertical and horizontal) and temporal heterogeneities in the energy budgets in an urban environment. (2) There is high inconsistency in measurement altitudes and resolutions among these three techniques. (3) It is still a challenge for remote sensing to quantitatively characterize the 3-D urban structure (e.g., urban canyon) and its spatiotemporal dynamics and (4) numerical models still need to be improved to be able to simulate the energy exchange processes associated with the complex urban structure. Accordingly, future studies should focus on promoting the comprehensive utilization of multiple methods to better 
understand the UHI phenomenon, and designing a decision-making framework to assess the influence of various urban planning policies on UHI.

\section{Summary}

This review shows an exponentially increasing trend in satellite-based SUHI publications since 2005, with large biases in the geographic areas, study time of day, study seasons, and research foci. Local-scale SUHI variations in the daytime and/or summer have received more research attention. Knowledge of SUHI variations and their relationship with air UHIs has been greatly enriched by the past SUHI studies even though some findings such as the relative significance of landscape composition, configuration, and the dominant factors for SUHI variations among cities remained highly disputed. UHI researchers currently face a series of challenges in using satellite LST data, including the differences between satellite-derived LST and air temperature, the impacts of clouds and other factors on LST data, the trade-off between spatial and temporal resolutions, the methods to quantify SUHI intensity, concurrent land cover, land use mapping, accuracy assessment, and attribution of SUHI. Worse still, the resultant uncertainties have been magnified by the wide applications of very limited datasets (e.g., using one image in a season or year) in the SUHI analyses. Given the availability of long-term archive/free data, a large number of images or time-series analyses are strongly recommended for future studies to increase the robustness of the findings. Considerable scope for improving the quality and quantity of LST data and analysis remains. We suggest that more attention be paid to the understudied regions/cities, the methods to calculate SUHI intensity, inter-annual variability and long-term trends of SUHI, scale issues of SUHI, SUHI-SubUHI relationships, and the integration of remote sensing data with field observation and numeric modeling in the future.

Supplementary Materials: The following are available online at http:/ /www.mdpi.com/2072-4292/11/1/48/s1, Table S1: List of the SUHI literature reviewed in this study, Text S1: The active journals of published SUHI literature.

Author Contributions: Conceptualization, D.Z. and J.X.; methodology, D.Z. and J.X.; writing—original draft preparation, D.Z., S.B., C.B., K.D., Y.Z., R.Y. and Z.Q.; writing—review and editing, J.X. and S.F.

Funding: This research was funded by the National Natural Science Foundation of China (Grant \#: 41501465, 41561038, and 41601196), the National Aeronautics and Space Administration (Grant \#: NNX14AI70G, 80NSSC18K1434, and NNX14AJ18G), the United States National Science Foundation (Grant \#: CBET-1803920), and the Jiangsu Key Laboratory of Agricultural Meteorology Foundation (Grant \#: JKLAM1804). The contribution of C. B. was financially supported by COKAP, which is a research project funded by DLR Projektträger and the German Federal Ministry of Transport and Digital Infrastructure (BMVI) (Grant \#: 50EW1707).

Acknowledgments: We thank Liangxia Zhang for her assistance with literature collection, and Dan Li for his comments on the outline of the review article.

Conflicts of Interest: The authors declare no conflict of interest.

$\begin{array}{ll}\text { Abbreviations } \\ \text { SUHI } & \text { Surface urban heat island } \\ \text { LST } & \text { Land surface temperature difference } \\ \text { UHI } & \text { Urban heat island } \\ \text { CLHI } & \text { Canopy layer heat island } \\ \text { BLHI } & \text { Boundary layer heat island } \\ \text { NDVI } & \text { Normalized difference vegetation index } \\ \text { ISA } & \text { Impervious surface area } \\ \text { USCs } & \text { Urban site characteristics } \\ \text { IBI } & \text { Index-based built-up index } \\ \text { NDBI } & \text { Normalized difference built-up index } \\ \text { UI } & \text { Urbanization index } \\ \text { FAI } & \text { Frontal area index } \\ \text { FAR } & \text { Floor area ratio }\end{array}$




$\begin{array}{ll}\text { SVF } & \text { Sky view factor } \\ \text { VF } & \text { Vegetation fraction } \\ \text { NDWI } & \text { Normalized difference water index } \\ \mathrm{T}_{\text {air }} & \text { Air temperature } \\ \text { LCZ } & \text { Local climate zone } \\ \text { SubUHI } & \text { Subsurface urban heat island } \\ \text { SubST } & \text { Subsurface temperature }\end{array}$

\section{References}

1. Oke, T.R. The energetic basis of the urban heat island. Q. J. R. Meteorol. Soc. 1982, 108, 1-24. [CrossRef]

2. Clinton, N.; Gong, P. Modis detected surface urban heat islands and sinks: Global locations and controls. Remote Sens. Environ. 2013, 134, 294-304. [CrossRef]

3. Li, X.; Zhou, Y.; Asrar, G.R.; Imhoff, M.; Li, X. The surface urban heat island response to urban expansion: A panel analysis for the conterminous United States. Sci. Total Environ. 2017, 605, 426-435. [CrossRef] [PubMed]

4. Peng, S.; Piao, S.; Ciais, P.; Friedlingstein, P.; Ottle, C.; Breon, F.-M.; Nan, H.; Zhou, L.; Myneni, R.B. Surface urban heat island across 419 global big cities. Environ. Sci. Technol. 2012, 46, 696-703. [CrossRef] [PubMed]

5. Zhou, B.; Rybski, D.; Kropp, J.P. The role of city size and urban form in the surface urban heat island. Sci. Rep. 2017, 7, 4791. [CrossRef] [PubMed]

6. Zhou, D.; Zhao, S.; Liu, S.; Zhang, L.; Zhu, C. Surface urban heat island in China's 32 major cities: Spatial patterns and drivers. Remote Sens. Environ. 2014, 152, 51-61. [CrossRef]

7. Rizwan, A.M.; Dennis, L.Y.C.; Liu, C. A review on the generation, determination and mitigation of urban heat island. J. Environ. Sci. 2008, 20, 120-128. [CrossRef]

8. Arnfield, A.J. Two decades of urban climate research: A review of turbulence, exchanges of energy and water, and the urban heat island. Int. J. Clim. 2003, 23, 1-26. [CrossRef]

9. Shepherd, J.M. A review of current investigations of urban-induced rainfall and recommendations for the future. Earth Interact. 2005, 9, 1-27. [CrossRef]

10. Stocker, T. Climate Change 2013: The Physical Science Basis: Working Group I Contribution to the Fifth Assessment Report of the Intergovernmental Panel on Climate Change; Cambridge University Press: Cambridge, UK, 2014.

11. Zhao, S.; Liu, S.; Zhou, D. Prevalent vegetation growth enhancement in urban environment. Proc. Natl. Acad. Sci. USA 2016, 113, 6313-6318. [CrossRef] [PubMed]

12. Zhou, D.; Zhao, S.; Zhang, L.; Liu, S. Remotely sensed assessment of urbanization effects on vegetation phenology in China's 32 major cities. Remote Sens. Environ. 2016, 176, 272-281. [CrossRef]

13. Grimm, N.B.; Faeth, S.H.; Golubiewski, N.E.; Redman, C.L.; Wu, J.; Bai, X.; Briggs, J.M. Global change and the ecology of cities. Science 2008, 319, 756-760. [CrossRef] [PubMed]

14. Patz, J.A.; Campbell-Lendrum, D.; Holloway, T.; Foley, J.A. Impact of regional climate change on human health. Nature 2005, 438, 310-317. [CrossRef] [PubMed]

15. Santamouris, M.; Cartalis, C.; Synnefa, A.; Kolokotsa, D. On the impact of urban heat island and global warming on the power demand and electricity consumption of buildings-A review. Energy Build. 2015, 98, 119-124. [CrossRef]

16. O'Loughlin, J.; Witmer, F.D.W.; Linke, A.M.; Laing, A.; Gettelman, A.; Dudhia, J. Climate variability and conflict risk in East Africa, 1990-2009. Proc. Natl. Acad. Sci. USA 2012, 109, 18344-18349. [CrossRef]

17. UN. United Nations Department of Economic Social Affairs Population Division. World Urbanization Prospects: The 2018 Revision; Online Edition; United Nations: New York, NY, USA, 2018.

18. Seto, K.C.; Güneralp, B.; Hutyra, L.R. Global forecasts of urban expansion to 2030 and direct impacts on biodiversity and carbon pools. Proc. Natl. Acad. Sci. USA 2012, 109, 16083-16088. [CrossRef]

19. Nichol, J.E.; Fung, W.Y.; Lam, K.-S.; Wong, M.S. Urban heat island diagnosis using ASTER satellite images and 'in situ' air temperature. Atmos. Res. 2009, 94, 276-284. [CrossRef]

20. Schwarz, N.; Schlink, U.; Franck, U.; Grossmann, K. Relationship of land surface and air temperatures and its implications for quantifying urban heat island indicators-an application for the city of Leipzig (Germany). Ecol. Indic. 2012, 18, 693-704. [CrossRef] 
21. Smoliak, B.V.; Snyder, P.K.; Twine, T.E.; Mykleby, P.M.; Hertel, W.F. Dense network observations of the twin cities canopy-layer urban heat island. J. Appl. Meteorol. Clim. 2015, 54, 1899-1917. [CrossRef]

22. Clay, R.; Guan, H.; Wild, N.; Bennett, J.; Vinodkumar; Ewenz, C. Urban heat island traverses in the city of Adelaide, South Australia. Urban Clim. 2016, 17, 89-101. [CrossRef]

23. Voogt, J. How Researchers Measure Urban Heat Islands. Available online: https://bit.ly/2V9aw Xv (accessed on 26 December 2018).

24. Mirzaei, P.A.; Haghighat, F. Approaches to study urban heat island-Abilities and limitations. Build. Environ. 2010, 45, 2192-2201. [CrossRef]

25. Anniballe, R.; Bonafoni, S.; Pichierri, M. Spatial and temporal trends of the surface and air heat island over Milan using MODIS data. Remote Sens. Environ. 2014, 150, 163-171. [CrossRef]

26. Jin, M.L.; Dickinson, R.E. Land surface skin temperature climatology: Benefitting from the strengths of satellite observations. Environ. Res. Lett. 2010, 5, 044004. [CrossRef]

27. Wang, K.; Jiang, S.; Wang, J.; Zhou, C.; Wang, X.; Lee, X. Comparing the diurnal and seasonal variabilities of atmospheric and surface urban heat islands based on the Beijing urban meteorological network. J. Geophys. Res. Atmos. 2017, 122, 2131-2154. [CrossRef]

28. Weng, Q. Thermal infrared remote sensing for urban climate and environmental studies: Methods, applications, and trends. ISPRS J. Photogramm. Remote Sens. 2009, 64, 335-344. [CrossRef]

29. Voogt, J.A.; Oke, T.R. Thermal remote sensing of urban climates. Remote Sens. Environ. 2003, 86, 370-384. [CrossRef]

30. Deilami, K.; Kamruzzaman, M.; Liu, Y. Urban heat island effect: A systematic review of spatio-temporal factors, data, methods, and mitigation measures. Int. J. Appl. Earth Obs. Geoinf. 2018, 67, 30-42. [CrossRef]

31. Ho, H.C.; Knudby, A.; Sirovyak, P.; Xu, Y.; Hodul, M.; Henderson, S.B. Mapping maximum urban air temperature on hot summer days. Remote Sens. Environ. 2014, 154, 38-45. [CrossRef]

32. Pichierri, M.; Bonafoni, S.; Biondi, R. Satellite air temperature estimation for monitoring the canopy layer heat island of Milan. Remote Sens. Environ. 2012, 127, 130-138. [CrossRef]

33. Rao, P.K. Remote sensing of urban "heat islands" from an environmental satellite. Bull. Am. Meteorol. Soc. 1972, 53, 647-648.

34. Gallo, K.P.; Tarpley, J.D.; McNab, A.L.; Karl, T.R. Assessment of urban heat islands: A satellite perspective. Atmos. Res. 1995, 37, 37-43. [CrossRef]

35. Tomlinson, C.J.; Chapman, L.; Thornes, J.E.; Baker, C. Remote sensing land surface temperature for meteorology and climatology: A review. Meteorol. Appl. 2011, 18, 296-306. [CrossRef]

36. Weng, Q.; Larson, R.C. Satellite remote sensing of urban heat islands: Current practice and prospects. In Geo-Spatial Technologies in Urban Environments; Jensen, R.R., Gatrell, J.D., McLean, D.D., Eds.; Springer: Berlin/Heidelberg, Germany, 2005; pp. 91-111.

37. Huang, Q.; Lu, Y. Urban heat island research from 1991 to 2015: A bibliometric analysis. Theor. Appl. Clim. 2018, 131, 1055-1067. [CrossRef]

38. Li, Z.; Tang, B.; Wu, H.; Ren, H.; Yan, G.; Wan, Z.; Trigo, I.F.; Sobrino, J.A. Satellite-derived land surface temperature: Current status and perspectives. Remote Sens. Environ. 2013, 131, 14-37. [CrossRef]

39. Mohamed, A.A.; Odindi, J.; Mutanga, O. Land surface temperature and emissivity estimation for urban heat island assessment using medium- and low-resolution space-borne sensors: A review. Geocarto Int. 2017, 32, 455-470. [CrossRef]

40. Bechtel, B.; Zaksek, K.; Hoshyaripour, G. Downscaling land surface temperature in an urban area: A case study for Hamburg, Germany. Remote Sens. 2012, 4, 3184-3200. [CrossRef]

41. Bonafoni, S. Downscaling of Landsat and MODIS land surface temperature over the heterogeneous urban area of Milan. IEEE J. Sel. Top. Appl. Earth Obs. Remote Sens. 2016, 9, 2019-2027. [CrossRef]

42. Unger, J. Intra-urban relationship between surface geometry and urban heat island: Review and new approach. Clim. Res. 2004, 27, 253-264. [CrossRef]

43. Stewart, I.D. A systematic review and scientific critique of methodology in modern urban heat island literature. Int. J. Clim. 2011, 31, 200-217. [CrossRef]

44. Mirzaei, P.A. Recent challenges in modeling of urban heat island. Sustain. Cities Soc. 2015, 19, $200-206$. [CrossRef]

45. Chapman, S.; Watson, J.E.M.; Salazar, A.; Thatcher, M.; McAlpine, C.A. The impact of urbanization and climate change on urban temperatures: A systematic review. Landsc. Ecol. 2017, 32, 1921-1935. [CrossRef] 
46. Gago, E.J.; Roldan, J.; Pacheco-Torres, R.; Ordóñez, J. The city and urban heat islands: A review of strategies to mitigate adverse effects. Renew Sustain. Energy Rev. 2013, 25, 749-758. [CrossRef]

47. Santamouris, M. Cooling the cities-A review of reflective and green roof mitigation technologies to fight heat island and improve comfort in urban environments. Sol. Energy 2014, 103, 682-703. [CrossRef]

48. Larsen, L. Urban climate and adaptation strategies. Front. Ecol. Environ. 2015, 13, 486-492. [CrossRef]

49. Jamei, E.; Rajagopalan, P.; Seyedmahmoudian, M.; Jamei, Y. Review on the impact of urban geometry and pedestrian level greening on outdoor thermal comfort. Renew. Sustain. Energy Rev. 2016, 54, 1002-1017. [CrossRef]

50. Zhang, P.; Imhoff, M.L.; Wolfe, R.E.; Bounoua, L. Characterizing urban heat islands of global settlements using MODIS and nighttime lights products. Can. J. Remote Sens. 2010, 36, 185-196. [CrossRef]

51. Zhang, Y.; Liang, S. Impacts of land cover transitions on surface temperature in China based on satellite observations. Environ. Res. Lett. 2018, 13. [CrossRef]

52. Imhoff, M.L.; Zhang, P.; Wolfe, R.E.; Bounoua, L. Remote sensing of the urban heat island effect across biomes in the continental USA. Remote Sens. Environ. 2010, 114, 504-513. [CrossRef]

53. Zhou, D.; Zhang, L.; Li, D.; Huang, D.; Zhu, C. Climate-vegetation control on the diurnal and seasonal variations of surface urban heat islands in China. Environ. Res. Lett. 2016, 11. [CrossRef]

54. Zhan, W.; Chen, Y.; Zhou, J.; Wang, J.; Liu, W.; Voogt, J.; Zhu, X.; Quan, J.; Li, J. Disaggregation of remotely sensed land surface temperature: Literature survey, taxonomy, issues, and caveats. Remote Sens. Environ. 2013, 131, 119-139. [CrossRef]

55. Matson, M.; McClain, E.P.; McGinnis, D.F.; Pritchard, J.A. Satellite detection of urban heat islands. Mon. Weather Rev. 1978, 106, 1725-1734. [CrossRef]

56. Matson, M.; Legeckis, R.V. Urban heat islands detected by satellite. Bull. Am. Meteorol. Soc. 1980, 61, 212.

57. Price, J.C. Assessment of the urban heat island effect through the use of satellite data. Mon. Weather Rev. 1979, 107, 1554-1557. [CrossRef]

58. Carnahan, W.H.; Larson, R.C. An analysis of an urban heat sink. Remote Sens. Environ. 1990, 33, 65-71. [CrossRef]

59. Wan, Z.; Zhang, Y.; Zhang, Q.; Li, Z.-L. Validation of the land-surface temperature products retrieved from terra moderate resolution imaging spectroradiometer data. Remote Sens. Environ. 2002, 83, 163-180. [CrossRef]

60. Zhang, X.; Friedl, M.A.; Schaaf, C.B.; Strahler, A.H.; Schneider, A. The footprint of urban climates on vegetation phenology. Geophys. Res. Lett. 2004, 31. [CrossRef]

61. Nichol, J. Remote sensing of urban heat islands by day and night. Photogramm. Eng. Remote Sens. 2005, 71, 613-621. [CrossRef]

62. Roth, M.; Oke, T.R.; Emery, W.J. Satellite-derived urban heat islands from three coastal cities and the utilization of such data in urban climatology. Int. J. Remote Sens. 1989, 10, 1699-1720. [CrossRef]

63. Gallo, K.P.; McNab, A.L.; Karl, T.R.; Brown, J.F.; Hood, J.J.; Tarpley, J.D. The use of a vegetation index for assessment of the urban heat island effect. Int. J. Remote Sens. 1993, 14, 2223-2230. [CrossRef]

64. Weng, Q.; Lu, D.; Schubring, J. Estimation of land surface temperature-vegetation abundance relationship for urban heat island studies. Remote Sens. Environ. 2004, 89, 467-483. [CrossRef]

65. Jin, M.L.; Dickinson, R.E.; Zhang, D.L. The footprint of urban areas on global climate as characterized by MODIS. J. Clim. 2005, 18, 1551-1565. [CrossRef]

66. Lu, D.; Weng, Q. Spectral mixture analysis of ASTER images for examining the relationship between urban thermal features and biophysical descriptors in Indianapolis, IN, USA. Remote Sens. Environ. 2006, 104, 157-167. [CrossRef]

67. Liu, H.; Weng, Q. Seasonal variations in the relationship between landscape pattern and land surface temperature in Indianapolis, IN, USA. Environ. Monit. Assess. 2008, 144, 199-219. [CrossRef] [PubMed]

68. Schwarz, N.; Lautenbach, S.; Seppelt, R. Exploring indicators for quantifying surface urban heat islands of european cities with MODIS land surface temperatures. Remote Sens. Environ. 2011, 115, 3175-3186. [CrossRef]

69. Hu, L.; Monaghan, A.; Voogt, J.A.; Barlage, M. A first satellite-based observational assessment of urban thermal anisotropy. Remote Sens. Environ. 2016, 181, 111-121. [CrossRef]

70. Chen, F.; Yang, S.; Yin, K.; Chan, P. Challenges to quantitative applications of Landsat observations for the urban thermal environment. J. Environ. Sci. 2017, 59, 80-88. [CrossRef] [PubMed] 
71. Young, N.E.; Anderson, R.S.; Chignell, S.M.; Vorster, A.G.; Lawrence, R.; Evangelista, P.H. A survival guide to Landsat preprocessing. Ecology 2017, 98, 920-932. [CrossRef] [PubMed]

72. Wulder, M.A.; White, J.C.; Loveland, T.R.; Woodcock, C.E.; Belward, A.S.; Cohen, W.B.; Fosnight, E.A.; Shaw, J.; Masek, J.G.; Roy, D.P. The global Landsat archive: Status, consolidation, and direction. Remote Sens. Environ. 2016, 185, 271-283. [CrossRef]

73. Popkin, G. US government considers charging for popular Earth-observing data. Nature 2018, 556, 417-418. [CrossRef]

74. Malakar, N.K.; Hulley, G.C.; Hook, S.J.; Laraby, K.; Cook, M.; Schott, J.R. An operational land surface temperature product for Landsat thermal data: Methodology and validation. IEEE Trans. Geosci. Remote Sens. 2018, 56, 5717-5735. [CrossRef]

75. Liao, W.L.; Liu, X.P.; Wang, D.G.; Sheng, Y.L. The impact of energy consumption on the surface urban heat island in China's 32 major cities. Remote Sens. 2017, 9, 250. [CrossRef]

76. Peng, J.; Ma, J.; Liu, Q.; Liu, Y.; Hu, Y.n.; Li, Y.; Yue, Y. Spatial-temporal change of land surface temperature across 285 cities in China: An urban-rural contrast perspective. Sci. Total Environ. 2018, 635, 487-497. [CrossRef] [PubMed]

77. Wan, Z.; Zhang, Y.; Wang, R.; Li, Z. Early Land-Surface Temperature Product Retrieved from MODIS Data, IGARSS 2001. Available online: https:/ / bit.ly/2V3S1lY (accessed on 26 December 2018).

78. Wan, Z.; Dozier, J. A generalized split-window algorithm for retrieving land-surface temperature from space. IEEE Trans. Geosci. Remote. Sens. 1996, 34, 892-905.

79. Hulley, G.; Veraverbeke, S.; Hook, S. Thermal-based techniques for land cover change detection using a new dynamic MODIS multispectral emissivity product (MOD21). Remote Sens. Environ. 2014, 140, 755-765. [CrossRef]

80. Abrams, M. The Advanced Spaceborne Thermal Emission and Reflection Radiometer (ASTER): Data products for the high spatial resolution imager on NASA's Terra platform. Int. J. Remote Sens. 2000, 21, 847-859. [CrossRef]

81. Zhang, Y.; Murray, A.T.; Turner, B.L., II. Optimizing green space locations to reduce daytime and nighttime urban heat island effects in Phoenix, Arizona. Landsc. Urban Plan. 2017, 165, 162-171. [CrossRef]

82. Zheng, B.; Myint, S.W.; Fan, C. Spatial configuration of anthropogenic land cover impacts on urban warming. Landsc. Urban Plan. 2014, 130, 104-111. [CrossRef]

83. Feng, X.; Myint, S.W. Exploring the effect of neighboring land cover pattern on land surface temperature of central building objects. Build. Environ. 2016, 95, 346-354. [CrossRef]

84. Fan, C.; Myint, S.W.; Zheng, B. Measuring the spatial arrangement of urban vegetation and its impacts on seasonal surface temperatures. Prog. Phys. Geogr. Earth Environ. 2015, 39, 199-219. [CrossRef]

85. Morabito, M.; Crisci, A.; Georgiadis, T.; Orlandini, S.; Munafo, M.; Congedo, L.; Rota, P.; Zazzi, M. Urban imperviousness effects on summer surface temperatures nearby residential buildings in different urban zones of Parma. Remote Sens. 2018, 10, 26. [CrossRef]

86. Abrams, M.; Tsu, H.; Hulley, G.; Iwao, K.; Pieri, D.; Cudahy, T.; Kargel, J. The Advanced Spaceborne Thermal Emission and Reflection Radiometer (ASTER) after fifteen years: Review of global products. Int. J. Appl. Earth Obs. Geoinf. 2015, 38, 292-301. [CrossRef]

87. Song, Y.; Wu, C. Examining the impact of urban biophysical composition and neighboring environment on surface urban heat island effect. Adv. Space Res. 2016, 57, 96-109. [CrossRef]

88. Wang, S.; Ma, Q.; Ding, H.; Liang, H. Detection of urban expansion and land surface temperature change using multi-temporal Landsat images. Resour. Conserv. Recycl. 2018, 128, 526-534. [CrossRef]

89. Zhang, L.; Meng, Q.; Sun, Z.; Sun, Y. Spatial and temporal analysis of the mitigating effects of industrial relocation on the surface urban heat island over China. ISPRS Int. J. Geoinf. 2017, 6, 121. [CrossRef]

90. Chen, W.; Zhang, Y.; Pengwang, C.; Gao, W. Evaluation of urbanization dynamics and its impacts on surface heat islands: A case study of Beijing, China. Remote Sens. 2017, 9, 453. [CrossRef]

91. Peng, J.; Jia, J.; Liu, Y.; Li, H.; Wu, J. Seasonal contrast of the dominant factors for spatial distribution of land surface temperature in urban areas. Remote Sens. Environ. 2018, 215, 255-267. [CrossRef]

92. Meng, Q.; Zhang, L.; Sun, Z.; Meng, F.; Wang, L.; Sun, Y. Characterizing spatial and temporal trends of surface urban heat island effect in an urban main built-up area: A 12-year case study in Beijing, China. Remote Sens. Environ. 2018, 204, 826-837. [CrossRef] 
93. Estoque, R.C.; Murayama, Y. Monitoring surface urban heat island formation in a tropical mountain city using Landsat data (1987-2015). ISPRS J. Photogramm. Remote Sens. 2017, 133, 18-29. [CrossRef]

94. Berger, C.; Rosentreter, J.; Voltersen, M.; Baumgart, C.; Schmullius, C.; Hese, S. Spatio-temporal analysis of the relationship between 2D/3D urban site characteristics and land surface temperature. Remote Sens. Environ. 2017, 193, 225-243. [CrossRef]

95. Peng, J.; Xie, P.; Liu, Y.; Ma, J. Urban thermal environment dynamics and associated landscape pattern factors: A case study in the Beijing metropolitan region. Remote Sens. Environ. 2016, 173, 145-155. [CrossRef]

96. Li, X.; Li, W.; Middel, A.; Harlan, S.L.; Brazel, A.J.; Turner, B.L., II. Remote sensing of the surface urban heat island and land architecture in Phoenix, Arizona: Combined effects of land composition and configuration and cadastral-demographic-economic factors. Remote Sens. Environ. 2016, 174, 233-243. [CrossRef]

97. Quan, J.; Chen, Y.; Zhan, W.; Wang, J.; Voogt, J.; Wang, M. Multi-temporal trajectory of the urban heat island centroid in Beijing, China based on a gaussian volume model. Remote Sens. Environ. 2014, 149, $33-46$. [CrossRef]

98. Kong, F.; Yin, H.; James, P.; Hutyra, L.R.; He, H.S. Effects of spatial pattern of greenspace on urban cooling in a large metropolitan area of Eastern China. Landsc. Urban Plan. 2014, 128, 35-47. [CrossRef]

99. Qiao, Z.; Tian, G.; Xiao, L. Diurnal and seasonal impacts of urbanization on the urban thermal environment: A case study of Beijing using MODIS data. ISPRS J. Photogramm. Remote Sens. 2013, 85, 93-101. [CrossRef]

100. Li, X.; Zhou, W.; Ouyang, Z. Relationship between land surface temperature and spatial pattern of greenspace: What are the effects of spatial resolution? Landsc. Urban Plan. 2013, 114, 1-8. [CrossRef]

101. Connors, J.P.; Galletti, C.S.; Chow, W.T.L. Landscape configuration and urban heat island effects: Assessing the relationship between landscape characteristics and land surface temperature in Phoenix, Arizona. Landsc. Ecol. 2013, 28, 271-283. [CrossRef]

102. Li, J.; Song, C.; Cao, L.; Zhu, F.; Meng, X.; Wu, J. Impacts of landscape structure on surface urban heat islands: A case study of Shanghai, China. Remote Sens. Environ. 2011, 115, 3249-3263. [CrossRef]

103. Naeem, S.; Cao, C.; Qazi, W.A.; Zamani, M.; Wei, C.; Acharya, B.K.; Rehman, A.U. Studying the association between green space characteristics and land surface temperature for sustainable urban environments: An analysis of Beijing and Islamabad. ISPRS Int. J. Geoinf. 2018, 7, 38. [CrossRef]

104. Madanian, M.; Soffianian, A.R.; Koupai, S.S.; Pourmanafi, S.; Momeni, M. Analyzing the effects of urban expansion on land surface temperature patterns by landscape metrics: A case study of Isfahan City, Iran. Environ. Monit. Assess. 2018, 190, 189. [CrossRef]

105. Buyantuyev, A.; Wu, J. Urban heat islands and landscape heterogeneity: Linking spatiotemporal variations in surface temperatures to land-cover and socioeconomic patterns. Landsc. Ecol. 2010, 25, 17-33. [CrossRef]

106. Liang, B.; Weng, Q. Multiscale analysis of census-based land surface temperature variations and determinants in Indianapolis, United States. J. Urban Plan. Dev. 2008, 134, 129-139. [CrossRef]

107. Yuan, F.; Bauer, M.E. Comparison of impervious surface area and normalized difference vegetation index as indicators of surface urban heat island effects in Landsat imagery. Remote Sens. Environ. 2007, 106, 375-386. [CrossRef]

108. Coutts, A.M.; Harris, R.J.; Thu, P.; Livesley, S.J.; Williams, N.S.G.; Tapper, N.J. Thermal infrared remote sensing of urban heat: Hotspots, vegetation, and an assessment of techniques for use in urban planning. Remote Sens. Environ. 2016, 186, 637-651. [CrossRef]

109. Yao, R.; Wang, L.; Huang, X.; Niu, Z.; Liu, F.; Wang, Q. Temporal trends of surface urban heat islands and associated determinants in major Chinese Cities. Sci. Total Environ. 2017, 609, 742-754. [CrossRef] [PubMed]

110. Dousset, B.; Gourmelon, F. Satellite multi-sensor data analysis of urban surface temperatures and landcover. ISPRS J. Photogramm. Remote Sens. 2003, 58, 43-54. [CrossRef]

111. Zhou, B.; Rybski, D.; Kropp, J.P. On the statistics of urban heat island intensity. Geophys. Res. Lett. 2013, 40, 5486-5491. [CrossRef]

112. Wang, J.; Huang, B.; Fu, D.; Atkinson, P.M. Spatiotemporal variation in surface urban heat island intensity and associated determinants across major Chinese Cities. Remote Sens. 2015, 7, 3670-3689. [CrossRef]

113. Zhao, S.; Zhou, D.; Liu, S. Data concurrency is required for estimating urban heat island intensity. Environ. Pollut. 2016, 208, 118-124. [CrossRef]

114. Miles, V.; Esau, I. Seasonal and spatial characteristics of urban heat islands (uhis) in Northern West Siberian Cities. Remote Sens. 2017, 9, 989. [CrossRef] 
115. Yang, Q.; Huang, X.; Li, J. Assessing the relationship between surface urban heat islands and landscape patterns across climatic zones in China. Sci. Rep. 2017, 7, 9337. [CrossRef]

116. Chen, X.; Zhao, H.; Li, P.; Yin, Z. Remote sensing image-based analysis of the relationship between urban heat island and land use/cover changes. Remote Sens. Environ. 2006, 104, 133-146. [CrossRef]

117. Haashemi, S.; Weng, Q.; Darvishi, A.; Alavipanah, S. Seasonal variations of the surface urban heat island in a semi-arid city. Remote Sens. 2016, 8, 352. [CrossRef]

118. Liu, Y.; Fang, X.; Xu, Y.; Zhang, S.; Luan, Q. Assessment of surface urban heat island across China's three main urban agglomerations. Theor. Appl. Clim. 2017, 133, 473-488. [CrossRef]

119. Quan, J.; Zhan, W.; Chen, Y.; Wang, M.; Wang, J. Time series decomposition of remotely sensed land surface temperature and investigation of trends and seasonal variations in surface urban heat islands. J. Geophys. Res. Atmos. 2016, 121, 2638-2657. [CrossRef]

120. Zhou, D.; Bonafoni, S.; Zhang, L.; Wang, R. Remote sensing of the urban heat island effect in a highly populated urban agglomeration area in East China. Sci. Total Environ. 2018, 628-629, 415-429. [CrossRef] [PubMed]

121. Zhou, D.; Zhang, L.; Hao, L.; Sun, G.; Liu, Y.; Zhu, C. Spatiotemporal trends of urban heat island effect along the urban development intensity gradient in China. Sci. Total Environ. 2016, 544, 617-626. [CrossRef]

122. Tomlinson, C.J.; Chapman, L.; Thornes, J.E.; Baker, C.J. Derivation of birmingham's summer surface urban heat island from MODIS satellite images. Int. J. Clim. 2012, 32, 214-224. [CrossRef]

123. Gallo, K.P.; McNab, A.L.; Karl, T.R.; Brown, J.F.; Hood, J.J.; Tarpley, J.D. The use of NOAA AVHRR data for assessment of the urban heat island effect. J. Appl. Meteorol. 1993, 32, 899-908. [CrossRef]

124. Zhang, P.; Bounoua, L.; Imhoff, M.L.; Wolfe, R.E.; Thome, K. Comparison of MODIS land surface temperature and air temperature over the continental USA meteorological stations. Can. J. Remote Sens. 2014, 40, 110-122.

125. Zhao, L.; Lee, X.; Smith, R.B.; Oleson, K. Strong contributions of local background climate to urban heat islands. Nature 2014, 511, 216-219. [CrossRef]

126. Cao, C.; Lee, X.; Liu, S.; Schultz, N.; Xiao, W.; Zhang, M.; Zhao, L. Urban heat islands in China enhanced by haze pollution. Nat. Commun. 2016, 7, 12509. [CrossRef] [PubMed]

127. Hung, T.; Uchihama, D.; Ochi, S.; Yasuoka, Y. Assessment with satellite data of the urban heat island effects in Asian mega cities. Int. J. Appl. Earth Obs. Geoinf. 2006, 8, 34-48.

128. Streutker, D.R. A remote sensing study of the urban heat island of Houston, Texas. Int. J. Remote Sens. 2002, 23, 2595-2608. [CrossRef]

129. Streutker, D.R. Satellite-measured growth of the urban heat island of Houston, Texas. Remote Sens. Environ. 2003, 85, 282-289. [CrossRef]

130. Rajasekar, U.; Weng, Q. Urban heat island monitoring and analysis using a non-parametric model: A case study of Indianapolis. ISPRS J. Photogramm. Remote Sens. 2009, 64, 86-96. [CrossRef]

131. Li, H.; Zhou, Y.; Li, X.; Meng, L.; Wang, X.; Wu, S.; Sodoudi, S. A new method to quantify surface urban heat island intensity. Sci. Total Environ. 2018, 624, 262-272. [CrossRef] [PubMed]

132. Oke, T.R. The urban energy balance. Prog. Phys. Geogr. Earth Environ. 1988, 12, 471-508. [CrossRef]

133. Estoque, R.C.; Murayama, Y.; Myint, S.W. Effects of landscape composition and pattern on land surface temperature: An urban heat island study in the megacities of Southeast Asia. Sci. Total Environ. 2017, 577, 349-359. [CrossRef]

134. Xie, M.; Wang, Y.; Chang, Q.; Fu, M.; Ye, M. Assessment of landscape patterns affecting land surface temperature in different biophysical gradients in Shenzhen, China. Urban Ecosyst. 2013, 16, 871-886. [CrossRef]

135. Zhou, W.; Qian, Y.; Li, X.; Li, W.; Han, L. Relationships between land cover and the surface urban heat island: Seasonal variability and effects of spatial and thematic resolution of land cover data on predicting land surface temperatures. Landsc. Ecol. 2014, 29, 153-167. [CrossRef]

136. Bao, T.; Li, X.; Zhang, J.; Zhang, Y.; Tian, S. Assessing the distribution of urban green spaces and its anisotropic cooling distance on urban heat island pattern in Baotou, China. ISPRS Int. J. Geoinf. 2016, 5, 12. [CrossRef]

137. Feyisa, G.L.; Dons, K.; Meilby, H. Efficiency of parks in mitigating urban heat island effect: An example from Addis Ababa. Landsc. Urban Plan. 2014, 123, 87-95. [CrossRef]

138. Guo, G.; Wu, Z.; Xiao, R.; Chen, Y.; Liu, X.; Zhang, X. Impacts of urban biophysical composition on land surface temperature in urban heat island clusters. Landsc. Urban Plan. 2015, 135, 1-10. [CrossRef] 
139. Heinl, M.; Hammerle, A.; Tappeiner, U.; Leitinger, G. Determinants of urban-rural land surface temperature differences-A landscape scale perspective. Landsc. Urban Plan. 2015, 134, 33-42. [CrossRef]

140. Yang, C.; He, X.; Yu, L.; Yang, J.; Yan, F.; Bu, K.; Chang, L.; Zhang, S. The cooling effect of urban parks and its monthly variations in a snow climate city. Remote Sens. 2017, 9, 1066. [CrossRef]

141. Du, H.; Cai, W.; Xu, Y.; Wang, Z.; Wang, Y.; Cai, Y. Quantifying the cool island effects of urban green spaces using remote sensing data. Urban For. Urban Green. 2017, 27, 24-31. [CrossRef]

142. Sun, R.; Chen, L. How can urban water bodies be designed for climate adaptation? Landsc. Urban Plan. 2012, 105, 27-33. [CrossRef]

143. Wang, X.; Cheng, H.; Xi, J.; Yang, G.; Zhao, Y. Relationship between park composition, vegetation characteristics and cool island effect. Sustainability 2018, 10, 587. [CrossRef]

144. Lazzarini, M.; Marpu, P.R.; Ghedira, H. Temperature-land cover interactions: The inversion of urban heat island phenomenon in desert city areas. Remote Sens. Environ. 2013, 130, 136-152. [CrossRef]

145. Pan, J. Analysis of human factors on urban heat island and simulation of urban thermal environment in Lanzhou city, China. J. Appl. Remote Sens. 2015, 9. [CrossRef]

146. Yue, W.; Liu, Y.; Fan, P.; Ye, X.; Wu, C. Assessing spatial pattern of urban thermal environment in Shanghai, China. Stoch. Environ. Res. Risk Assess. 2012, 26, 899-911. [CrossRef]

147. Gage, E.A.; Cooper, D.J. Urban forest structure and land cover composition effects on land surface temperature in a semi-arid suburban area. Urban For. Urban Green. 2017, 28, 28-35. [CrossRef]

148. Weng, Q.; Liu, H.; Liang, B.; Lu, D. The spatial variations of urban land surface temperatures: Pertinent factors, zoning effect, and seasonal variability. IEEE J. Sel. Top. Appl. Earth Obs. Remote Sens. 2008, 1, 154-166. [CrossRef]

149. Ranagalage, M.; Estoque, R.C.; Zhang, X.; Murayama, Y. Spatial changes of urban heat island formation in the colombo district, Sri Lanka: Implications for sustainability planning. Sustainability 2018, 10, 1367. [CrossRef]

150. Li, W.; Cao, Q.; Lang, K.; Wu, J. Linking potential heat source and sink to urban heat island: Heterogeneous effects of landscape pattern on land surface temperature. Sci. Total Environ. 2017, 586, 457-465. [CrossRef] [PubMed]

151. Chen, Y.-C.; Chiu, H.-W.; Su, Y.-F.; Wu, Y.-C.; Cheng, K.-S. Does urbanization increase diurnal land surface temperature variation? Evidence and implications. Landsc. Urban Plan. 2017, 157, 247-258. [CrossRef]

152. Yu, Z.; Guo, X.; Zeng, Y.; Koga, M.; Vejre, H. Variations in land surface temperature and cooling efficiency of green space in rapid urbanization: The case of Fuzhou City, China. Urban For. Urban Green. 2018, 29, 113-121. [CrossRef]

153. Bhang, K.J.; Park, S.-S. Evaluation of the surface temperature variation with surface settings on the urban heat island in Seoul, Korea, using Landsat-7 ETM+ and spot. IEEE Geosci. Remote Sens. Lett. 2009, 6, 708-712. [CrossRef]

154. Guo, G.; Zhou, X.; Wu, Z.; Xiao, R.; Chen, Y. Characterizing the impact of urban morphology heterogeneity on land surface temperature in Guangzhou, China. Environ. Model. Softw. 2016, 84, 427-439. [CrossRef]

155. Kuang, W.; Liu, Y.; Dou, Y.; Chi, W.; Chen, G.; Gao, C.; Yang, T.; Liu, J.; Zhang, R. What are hot and what are not in an urban landscape: Quantifying and explaining the land surface temperature pattern in Beijing, China. Landsc. Ecol. 2015, 30, 357-373. [CrossRef]

156. Yin, C.; Yuan, M.; Lu, Y.; Huang, Y.; Liu, Y. Effects of urban form on the urban heat island effect based on spatial regression model. Sci. Total Environ. 2018, 634, 696-704. [CrossRef]

157. Zhou, W.; Huang, G.; Cadenasso, M.L. Does spatial configuration matter? Understanding the effects of land cover pattern on land surface temperature in urban landscapes. Landsc. Urban Plan. 2011, 102, 54-63. [CrossRef]

158. Nassar, A.K.; Blackburn, G.A.; Whyatt, J.D. Dynamics and controls of urban heat sink and island phenomena in a desert city: Development of a local climate zone scheme using remotely-sensed inputs. Int. J. Appl. Earth Obs. Geoinf. 2016, 51, 76-90. [CrossRef]

159. Scarano, M.; Sobrino, J.A. On the relationship between the sky view factor and the land surface temperature derived by Landsat-8 images in Bari, Italy. Int. J. Remote Sens. 2015, 36, 4820-4835. [CrossRef]

160. Asgarian, A.; Amiri, B.J.; Sakieh, Y. Assessing the effect of green cover spatial patterns on urban land surface temperature using landscape metrics approach. Urban Ecosyst. 2015, 18, 209-222. [CrossRef] 
161. Lin, W.; Yu, T.; Chang, X.; Wu, W.; Zhang, Y. Calculating cooling extents of green parks using remote sensing: Method and test. Landsc. Urban Plan. 2015, 134, 66-75. [CrossRef]

162. Alavipanah, S.; Wegmann, M.; Qureshi, S.; Weng, Q.; Koellner, T. The role of vegetation in mitigating urban land surface temperatures: A case study of Munich, Germany during the warm season. Sustainability 2015, 7, 4689-4706. [CrossRef]

163. Li, X.; Zhou, W.; Ouyang, Z.; Xu, W.; Zheng, H. Spatial pattern of greenspace affects land surface temperature: Evidence from the heavily urbanized Beijing metropolitan area, China. Landsc. Ecol. 2012, 27, 887-898. [CrossRef]

164. Gage, E.A.; Cooper, D.J. Relationships between landscape pattern metrics, vertical structure and surface urban heat island formation in a Colorado suburb. Urban Ecosyst. 2017, 20, 1229-1238. [CrossRef]

165. Adams, M.P.; Smith, P.L. A systematic approach to model the influence of the type and density of vegetation cover on urban heat using remote sensing. Landsc. Urban Plan. 2014, 132, 47-54. [CrossRef]

166. Wu, H.; Ye, L.-P.; Shi, W.-Z.; Clarke, K.C. Assessing the effects of land use spatial structure on urban heat islands using HJ-1B remote sensing imagery in Wuhan, China. Int. J. Appl. Earth Obs. Geoinf. 2014, 32, 67-78. [CrossRef]

167. Zhang, Y.; Balzter, H.; Liu, B.; Chen, Y. Analyzing the impacts of urbanization and seasonal variation on land surface temperature based on subpixel fractional covers using Landsat images. IEEE J. Sel. Top. Appl. Earth Obs. Remote Sens. 2017, 10, 1344-1356. [CrossRef]

168. Cai, Z.; Han, G.; Chen, M. Do water bodies play an important role in the relationship between urban form and land surface temperature? Sustain. Cities Soc. 2018, 39, 487-498. [CrossRef]

169. Chen, A.; Yao, L.; Sun, R.; Chen, L. How many metrics are required to identify the effects of the landscape pattern on land surface temperature? Ecol. Indic. 2014, 45, 424-433. [CrossRef]

170. Chen, Y.; Yu, S. Impacts of urban landscape patterns on urban thermal variations in Guangzhou, China. Int. J. Appl. Earth Obs. Geoinf. 2017, 54, 65-71. [CrossRef]

171. Du, S.; Xiong, Z.; Wang, Y.-C.; Guo, L. Quantifying the multilevel effects of landscape composition and configuration on land surface temperature. Remote Sens. Environ. 2016, 178, 84-92. [CrossRef]

172. Li, X.; Kamarianakis, Y.; Ouyang, Y.; Turner, B.L., II; Brazel, A. On the association between land system architecture and land surface temperatures: Evidence from a desert metropolis-Phoenix, AZ, USA. Landsc. Urban Plan. 2017, 163, 107-120. [CrossRef]

173. Zhou, W.; Wang, J.; Cadenasso, M.L. Effects of the spatial configuration of trees on urban heat mitigation: A comparative study. Remote Sens. Environ. 2017, 195, 1-12. [CrossRef]

174. Chen, A.; Yao, X.A.; Sun, R.; Chen, L. Effect of urban green patterns on surface urban cool islands and its seasonal variations. Urban For. Urban Green. 2014, 13, 646-654. [CrossRef]

175. Maimaitiyiming, M.; Ghulam, A.; Tiyip, T.; Pla, F.; Latorre-Carmona, P.; Halik, U.; Sawut, M.; Caetano, M. Effects of green space spatial pattern on land surface temperature: Implications for sustainable urban planning and climate change adaptation. ISPRS J. Photogramm. Remote Sens. 2014, 89, 59-66. [CrossRef]

176. Liu, Y.; Peng, J.; Wang, Y. Application of partial least squares regression in detecting the important landscape indicators determining urban land surface temperature variation. Landsc. Ecol. 2018, 33, 1133-1145. [CrossRef]

177. Zhang, P.; Imhoff, M.L.; Bounoua, L.; Wolfe, R.E. Exploring the influence of impervious surface density and shape on urban heat islands in the northeast United States using MODIS and Landsat. Can. J. Remote Sens. 2012, 38, 441-451.

178. Du, H.; Wang, D.; Wang, Y.; Zhao, X.; Qin, F.; Jiang, H.; Cai, Y. Influences of land cover types, meteorological conditions, anthropogenic heat and urban area on surface urban heat island in the Yangtze River Delta urban agglomeration. Sci. Total Environ. 2016, 571, 461-470. [CrossRef] [PubMed]

179. Benas, N.; Chrysoulakis, N.; Cartalis, C. Trends of urban surface temperature and heat island characteristics in the Mediterranean. Theor. Appl. Clim. 2017, 130, 807-816. [CrossRef]

180. Ma, Q.; Wu, J.; He, C. A hierarchical analysis of the relationship between urban impervious surfaces and land surface temperatures: Spatial scale dependence, temporal variations, and bioclimatic modulation. Landsc. Ecol. 2016, 31, 1139-1153. [CrossRef]

181. Kumar, R.; Mishra, V.; Buzan, J.; Kumar, R.; Shindell, D.; Huber, M. Dominant control of agriculture and irrigation on urban heat island in India. Sci. Rep. 2017, 7, 14054. [CrossRef] 
182. Shastri, H.; Barik, B.; Ghosh, S.; Venkataraman, C.; Sadavarte, P. Flip flop of day-night and summer-winter surface urban heat island intensity in India. Sci. Rep. 2017, 7, 40178. [CrossRef]

183. Schwarz, N.; Manceur, A.M. Analyzing the influence of urban forms on surface urban heat islands in Europe. J. Urban Plan. Dev. 2015, 141. [CrossRef]

184. Cui, Y.; Xu, X.; Dong, J.; Qin, Y. Influence of urbanization factors on surface urban heat island intensity: A comparison of countries at different developmental phases. Sustainability 2016, 8, 706. [CrossRef]

185. Lazzarini, M.; Molini, A.; Marpu, P.R.; Ouarda, T.B.M.J.; Ghedira, H. Urban climate modifications in hot desert cities: The role of land cover, local climate, and seasonality. Geophys. Res. Lett. 2015, 42, 9980-9989. [CrossRef]

186. Zhou, D.; Li, D.; Sun, G.; Zhang, L.; Liu, Y.; Hao, L. Contrasting effects of urbanization and agriculture on surface temperature in Eastern China. J. Geophys. Res. Atmos. 2016, 121, 9597-9606. [CrossRef]

187. Zhang, J.; Wang, Y. Study of the relationships between the spatial extent of surface urban heat islands and urban characteristic factors based on Landsat ETM Plus data. Sensors 2008, 8, 7453-7468. [CrossRef]

188. Fabrizi, R.; Bonafoni, S.; Biondi, R. Satellite and ground-based sensors for the urban heat island analysis in the city of Rome. Remote Sens. 2010, 2, 1400-1415. [CrossRef]

189. Sun, H.; Chen, Y.; Zhan, W. Comparing surface- and canopy-layer urban heat islands over Beijing using MODIS data. Int. J. Remote Sens. 2015, 36, 5448-5465. [CrossRef]

190. Huang, W.; Li, J.; Guo, Q.; Mansaray, L.R.; Li, X.; Huang, J. A satellite-derived climatological analysis of urban heat island over Shanghai during 2000-2013. Remote. Sens. 2017, 9, 641. [CrossRef]

191. Li, X.; Zhou, Y.; Asrar, G.R.; Zhu, Z. Developing a $1 \mathrm{~km}$ resolution daily air temperature dataset for urban and surrounding areas in the conterminous United States. Remote Sens. Environ. 2018, 215, 74-84. [CrossRef]

192. Bonafoni, S.; Baldinelli, G.; Verducci, P.; Presciutti, A. Remote sensing techniques for urban heating analysis: A case study of sustainable construction at district level. Sustainability 2017, 9, 1308. [CrossRef]

193. Zhang, F.; Cai, X.; Thornes, J.E. Birmingham's air and surface urban heat islands associated with lamb weather types and cloudless anticyclonic conditions. Prog. Phys. Geogr. Earth Environ. 2014, 38, 431-447. [CrossRef]

194. Azevedo, J.A.; Chapman, L.; Muller, C.L. Quantifying the daytime and night-time urban heat island in Birmingham, UK: A comparison of satellite derived land surface temperature and high resolution air temperature observations. Remote Sens. 2016, 8, 153. [CrossRef]

195. Li, L.; Huang, X.; Li, J.; Wen, D. Quantifying the spatiotemporal trends of canopy layer heat island (CLHI) and its driving factors over Wuhan, China with satellite remote sensing. Remote Sens. 2017, 9, 536. [CrossRef]

196. Sheng, L.; Tang, X.; You, H.; Gu, Q.; Hu, H. Comparison of the urban heat island intensity quantified by using air temperature and Landsat land surface temperature in Hangzhou, China. Ecol. Indic. 2017, 72, 738-746. [CrossRef]

197. Becker, F.; Li, Z.L. Surface temperature and emissivity at various scales: Definition, measurement and related problems. Remote Sens. Rev. 1995, 12, 225-253. [CrossRef]

198. Sobrino, J.A.; Oltra-Carrio, R.; Soria, G.; Carlos Jimenez-Munoz, J.; Franch, B.; Hidalgo, V.; Mattar, C.; Julien, Y.; Cuenca, J.; Romaguera, M.; et al. Evaluation of the surface urban heat island effect in the city of madrid by thermal remote sensing. Int. J. Remote Sens. 2013, 34, 3177-3192. [CrossRef]

199. Hafner, J.; Kidder, S.Q. Urban heat island modeling in conjunction with satellite-derived surface/soil parameters. J. Appl. Meteorol. 1999, 38, 448-465. [CrossRef]

200. Hu, L.; Brunsell, N.A.; Monaghan, A.J.; Barlage, M.; Wilhelmi, O.V. How can we use MODIS land surface temperature to validate long-term urban model simulations? J. Geophys. Res. Atmos. 2014, 119, 3185-3201. [CrossRef]

201. White-Newsome, J.L.; Brines, S.J.; Brown, D.G.; Dvonch, J.T.; Gronlund, C.J.; Zhang, K.; Oswald, E.M.; O'Neill, M.S. Validating satellite-derived land surface temperature with in situ measurements: A public health perspective. Environ. Health Perspect. 2013, 121, 925-931. [CrossRef] [PubMed]

202. Wan, Z. New refinements and validation of the Collection-6 MODIS land-surface temperature/emissivity product. Remote Sens. Environ. 2014, 140, 36-45. [CrossRef]

203. Gawuc, L.; Struzewska, J. Impact of MODIS quality control on temporally aggregated urban surface temperature and long-term surface urban heat island intensity. Remote Sens. 2016, 8, 374. [CrossRef] 
204. Williamson, S.N.; Hik, D.S.; Gamon, J.A.; Kavanaugh, J.L.; Koh, S. Evaluating cloud contamination in clear-sky MODIS Terra daytime land surface temperatures using ground-based meteorology station observations. J. Clim. 2013, 26, 1551-1560. [CrossRef]

205. Li, X.; Zhou, Y.; Asrar, G.R.; Zhu, Z. Creating a seamless $1 \mathrm{~km}$ resolution daily land surface temperature dataset for urban and surrounding areas in the conterminous United States. Remote Sens. Environ. 2018, 206, 84-97. [CrossRef]

206. Li, D.; Bou-Zeid, E. Synergistic interactions between urban heat islands and heat waves: The impact in cities is larger than the sum of its parts. J. Appl. Meteorol. Clim. 2013, 52, 2051-2064. [CrossRef]

207. Hu, L.; Brunsell, N.A. The impact of temporal aggregation of land surface temperature data for surface urban heat island (SUHI) monitoring. Remote Sens. Environ. 2013, 134, 162-174. [CrossRef]

208. Huang, F.; Zhan, W.; Voogt, J.; Hu, L.; Wang, Z.; Quan, J.; Ju, W.; Guo, Z. Temporal upscaling of surface urban heat island by incorporating an annual temperature cycle model: A tale of two cities. Remote Sens. Environ. 2016, 186, 1-12. [CrossRef]

209. Lai, J.; Zhan, W.; Huang, F.; Quan, J.; Hu, L.; Gao, L.; Ju, W. Does quality control matter? Surface urban heat island intensity variations estimated by satellite-derived land surface temperature products. ISPRS J. Photogramm. Remote Sens. 2018, 139, 212-227. [CrossRef]

210. Weng, Q.; Fu, P. Modeling annual parameters of clear-sky land surface temperature variations and evaluating the impact of cloud cover using time series of Landsat TIR data. Remote Sens. Environ. 2014, 140, 267-278. [CrossRef]

211. Shen, H.; Li, X.; Cheng, Q.; Zeng, C.; Yang, G.; Li, H.; Zhang, L. Missing information reconstruction of remote sensing data: A technical review. IEEE Geosci. Remote Sens. Mag. 2015, 3, 61-85. [CrossRef]

212. Liu, H.; Weng, Q. Scaling effect of fused ASTER-MODIS land surface temperature in an urban environment. Sensors 2018, 18, 4058. [CrossRef]

213. Shen, H.; Huang, L.; Zhang, L.; Wu, P.; Zeng, C. Long-term and fine-scale satellite monitoring of the urban heat island effect by the fusion of multi-temporal and multi-sensor remote sensed data: A 26-year case study of the city of Wuhan in China. Remote Sens. Environ. 2016, 172, 109-125. [CrossRef]

214. Liu, K.; Su, H.; Li, X.; Wang, W.; Yang, L.; Liang, H. Quantifying spatial-temporal pattern of urban heat island in Beijing: An improved assessment using land surface temperature (LST) time series observations from Landsat, MODIS, and Chinese new satellite Gaofen-1. IEEE J. Sel. Top. Appl. Earth Obs. Remote Sens. 2016, 9, 2028-2042. [CrossRef]

215. Weng, Q.; Fu, P.; Gao, F. Generating daily land surface temperature at Landsat resolution by fusing Landsat and MODIS data. Remote Sens. Environ. 2014, 145, 55-67. [CrossRef]

216. Crosson, W.L.; Al-Hamdan, M.Z.; Hemmings, S.N.; Wade, G.M. A daily merged MODIS Aqua-Terra land surface temperature data set for the conterminous United States. Remote Sens. Environ. 2012, 119, 315-324. [CrossRef]

217. Fan, X.; Liu, H.; Liu, G.; Li, S. Reconstruction of MODIS land-surface temperature in a flat terrain and fragmented landscape. Int. J. Remote Sens. 2014, 35, 7857-7877. [CrossRef]

218. Kilibarda, M.; Hengl, T.; Heuvelink, G.B.; Gräler, B.; Pebesma, E.; Perčec Tadić, M.; Bajat, B. Spatio-temporal interpolation of daily temperatures for global land areas at $1 \mathrm{~km}$ resolution. J. Geophys. Res. Atmos. 2014, 119, 2294-2313. [CrossRef]

219. Weiss, D.J.; Atkinson, P.M.; Bhatt, S.; Mappin, B.; Hay, S.I.; Gething, P.W. An effective approach for gap-filling continental scale remotely sensed time-series. ISPRS J. Photogramm. Remote Sens. 2014, 98, 106-118. [CrossRef] [PubMed]

220. Metz, M.; Andreo, V.; Neteler, M. A new fully gap-free time series of land surface temperature from MODIS LST data. Remote Sens. 2017, 9, 1333. [CrossRef]

221. Kou, X.; Jiang, L.; Bo, Y.; Yan, S.; Chai, L. Estimation of land surface temperature through blending MODIS and AMSR-E data with the Bayesian maximum entropy method. Remote Sens. 2016, 8, 105. [CrossRef]

222. Duan, S.; Li, Z.; Leng, P. A framework for the retrieval of all-weather land surface temperature at a high spatial resolution from polar-orbiting thermal infrared and passive microwave data. Remote Sens. Environ. 2017, 195, 107-117. [CrossRef]

223. Stathopoulou, M.; Cartalis, C. Downscaling AVHRR land surface temperatures for improved surface urban heat island intensity estimation. Remote Sens. Environ. 2009, 113, 2592-2605. [CrossRef] 
224. Keramitsoglou, I.; Daglis, I.A.; Amiridis, V.; Chrysoulakis, N.; Ceriola, G.; Manunta, P.; Maiheu, B.; De Ridder, K.; Lauwaet, D.; Paganini, M. Evaluation of satellite-derived products for the characterization of the urban thermal environment. J. Appl. Remote Sens. 2012, 6. [CrossRef]

225. Song, J.; Du, S.; Feng, X.; Guo, L. The relationships between landscape compositions and land surface temperature: Quantifying their resolution sensitivity with spatial regression models. Landsc. Urban Plan. 2014, 123, 145-157. [CrossRef]

226. Sobrino, J.A.; Oltra-Carrio, R.; Soria, G.; Bianchi, R.; Paganini, M. Impact of spatial resolution and satellite overpass time on evaluation of the surface urban heat island effects. Remote Sens. Environ. 2012, 117, 50-56. [CrossRef]

227. Huang, B.; Wang, J.; Song, H.; Fu, D.; Wong, K. Generating high spatiotemporal resolution land surface temperature for urban heat island monitoring. IEEE Geosci. Remote Sens. Lett. 2013, 10, 1011-1015. [CrossRef]

228. Chudnovsky, A.; Ben-Dor, E.; Saaroni, H. Diurnal thermal behavior of selected urban objects using remote sensing measurements. Energy Build. 2004, 36, 1063-1074. [CrossRef]

229. Nichol, J. An emissivity modulation method for spatial enhancement of thermal satellite images in urban heat island analysis. Photogramm. Eng. Remote Sens. 2009, 75, 547-556. [CrossRef]

230. Essa, W.; van der Kwast, J.; Verbeiren, B.; Batelaan, O. Downscaling of thermal images over urban areas using the land surface temperature-impervious percentage relationship. Int. J. Appl. Earth Obs. Geoinf. 2013, 23, 95-108. [CrossRef]

231. Weng, Q.; Fu, P. Modeling diurnal land temperature cycles over Los Angeles using downscaled GOES imagery. ISPRS J. Photogramm. Remote Sens. 2014, 97, 78-88. [CrossRef]

232. Sandau, R.; Brieß, K.; D’Errico, M. Small satellites for global coverage: Potential and limits. ISPRS J. Photogramm. Remote Sens. 2010, 65, 492-504. [CrossRef]

233. Yao, R.; Wang, L.; Huang, X.; Niu, Y.; Chen, Y.; Niu, Z. The influence of different data and method on estimating the surface urban heat island intensity. Ecol. Indic. 2018, 89, 45-55. [CrossRef]

234. Zhou, D.; Zhao, S.; Zhang, L.; Sun, G.; Liu, Y. The footprint of urban heat island effect in China. Sci. Rep. 2015, 5, 11160. [CrossRef] [PubMed]

235. Stewart, I.D.; Oke, T.R. Local climate zones for urban temperature studies. Bull. Am. Meteorol. Soc. 2012, 93, 1879-1900. [CrossRef]

236. Schneider, A.; Friedl, M.A.; Potere, D. Mapping global urban areas using MODIS 500-m data: New methods and datasets based on 'urban ecoregions'. Remote Sens. Environ. 2010, 114, 1733-1746. [CrossRef]

237. Zhou, Y.; Li, X.; Asrar, G.R.; Smith, S.J.; Imhoff, M. A global record of annual urban dynamics (1992-2013) from nighttime lights. Remote Sens. Environ. 2018, 219, 206-220. [CrossRef]

238. Tang, B.; Shao, K.; Li, Z.; Wu, H.; Nerry, F.; Zhou, G. Estimation and validation of land surface temperatures from Chinese second-generation polar-orbit FY-3A VIRR data. Remote Sens. 2015, 7, 3250-3273. [CrossRef]

239. Rigo, G.; Parlow, E.; Oesch, D. Validation of satellite observed thermal emission with in-situ measurements over an urban surface. Remote Sens. Environ. 2006, 104, 201-210. [CrossRef]

240. Song, B.; Park, K. Validation of ASTER surface temperature data with in situ measurements to evaluate heat islands in complex urban areas. Adv. Meteorol. 2014, 2014, 620410. [CrossRef]

241. Deilami, K.; Kamruzzaman, M.; Hayes, J.F. Correlation or causality between land cover patterns and the urban heat island effect? Evidence from Brisbane, Australia. Remote Sens. 2016, 8, 716. [CrossRef]

242. Sun, R.; Wang, Y.; Chen, L. A distributed model for quantifying temporal-spatial patterns of anthropogenic heat based on energy consumption. J. Clean. Prod. 2018, 170, 601-609. [CrossRef]

243. Madanian, M.; Soffianian, A.R.; Koupai, S.S.; Pourmanafi, S.; Momeni, M. The study of thermal pattern changes using Landsat-derived land surface temperature in the central part of Isfahan province. Sustain. Cities Soc. 2018, 39, 650-661. [CrossRef]

244. Wang, Y.-C.; Hu, B.K.H.; Myint, S.W.; Feng, C.-C.; Chow, W.T.L.; Passy, P.F. Patterns of land change and their potential impacts on land surface temperature change in Yangon, Myanmar. Sci. Total Environ. 2018, 643, 738-750. [CrossRef]

245. Fu, P.; Weng, Q. Consistent land surface temperature data generation from irregularly spaced Landsat imagery. Remote Sens. Environ. 2016, 184, 175-187. [CrossRef]

246. Field, C.B. Climate Change 2014-Impacts, Adaptation and Vulnerability: Regional Aspects; Cambridge University Press: Cambridge, UK, 2014. 
247. Center for International Earth Science Information Network-CIESIN-Columbia University. Gridded Population of the World, Version 4 (gpwo4): Population Density, Revision 10; NASA Socioeconomic Data and Applications Center (SEDAC): Palisades, NY, USA, 2017.

248. Zhou, D.; Zhang, L.; Wang, R. Administrative-hierarchical urban land expansion in China: Urban agglomeration in the Yangtze River Delta. J. Urban Plan. Dev. 2018, 144, 05018018. [CrossRef]

249. Stewart, I.D.; Oke, T.R.; Krayenhoff, E.S. Evaluation of the 'local climate zone' scheme using temperature observations and model simulations. Int. J. Clim. 2014, 34, 1062-1080. [CrossRef]

250. Hu, L.; Brunsell, N.A. A new perspective to assess the urban heat island through remotely sensed atmospheric profiles. Remote Sens. Environ. 2015, 158, 393-406. [CrossRef]

251. Bonafoni, S.; Keeratikasikorn, C. Land surface temperature and urban density: Multiyear modeling and relationship analysis using MODIS and Landsat data. Remote Sens. 2018, 10, 1471. [CrossRef]

252. Qiao, Z.; Tian, G.; Zhang, L.; Xu, X. Influences of urban expansion on urban heat island in Beijing during 1989-2010. Adv. Meteorol. 2014, 2014, 1-11. [CrossRef]

253. Lo, C.P. Land-use and land-cover change, urban heat island phenomenon, and health implications. Photogramm. Eng. Remote Sens. 2003, 69, 1053-1063. [CrossRef]

254. Amiri, R.; Weng, Q.; Alimohammadi, A.; Alavipanah, S.K. Spatial-temporal dynamics of land surface temperature in relation to fractional vegetation cover and land use/cover in the Tabriz urban area, Iran. Remote Sens. Environ. 2009, 113, 2606-2617. [CrossRef]

255. Jiang, Y.; Fu, P.; Weng, Q. Assessing the impacts of urbanization-associated land use/cover change on land surface temperature and surface moisture: A case study in the midwestern United States. Remote Sens. 2015, 7, 4880-4898. [CrossRef]

256. Barat, A.; Kumar, S.; Kumar, P.; Parth Sarthi, P. Characteristics of surface urban heat island (SUHI) over the gangetic plain of Bihar, India. Asia-Pac. J. Atmos. Sci. 2018, 54, 205-214. [CrossRef]

257. Keeratikasikorn, C.; Bonafoni, S. Satellite images and Gaussian parameterization for an extensive analysis of urban heat islands in Thailand. Remote Sens. 2018, 10, 665. [CrossRef]

258. Quan, J.; Zhan, W.; Ma, T.; Du, Y.; Guo, Z.; Qin, B. An integrated model for generating hourly Landsat-like land surface temperatures over heterogeneous landscapes. Remote Sens. Environ. 2018, 206, 403-423. [CrossRef]

259. Cao, C.; Lam, N.S.-N. Understanding the scale and resolution effects in remote sensing and GIS. Scale Remote Sens. GIS 1997, 57, 72 .

260. Liu, H.; Weng, Q. Scaling effect on the relationship between landscape pattern and land surface temperature: A case study of Indianapolis, United States. Photogramm. Eng. Remote Sens. 2009, 75, 291-304. [CrossRef]

261. Zhang, X.; Zhong, T.; Wang, K.; Cheng, Z. Scaling of impervious surface area and vegetation as indicators to urban land surface temperature using satellite data. Int. J. Remote Sens. 2009, 30, 841-859. [CrossRef]

262. Li, S.; Zhao, Z.; Xie, M.; Wang, Y. Investigating spatial non-stationary and scale-dependent relationships between urban surface temperature and environmental factors using geographically weighted regression. Environ. Model. Softw. 2010, 25, 1789-1800. [CrossRef]

263. Luo, X.; Li, W. Scale effect analysis of the relationships between urban heat island and impact factors: Case study in Chongqing. J. Appl. Remote Sens. 2014, 8, 084995. [CrossRef]

264. Ferguson, G.; Woodbury, A.D. Urban heat island in the subsurface. Geophys. Res. Lett. 2007, 34. [CrossRef]

265. Zhan, W.; Ju, W.; Hai, S.; Ferguson, G.; Quan, J.; Tang, C.; Guo, Z.; Kong, F. Satellite-derived subsurface urban heat island. Environ. Sci. Technol. 2014, 48, 12134-12140. [CrossRef]

266. Huang, S.; Taniguchi, M.; Yamano, M.; Wang, C. Detecting urbanization effects on surface and subsurface thermal environment-A case study of Osaka. Sci. Total Environ. 2009, 407, 3142-3152. [CrossRef] [PubMed]

267. Shi, B.; Tang, C.-S.; Gao, L.; Liu, C.; Wang, B.-J. Observation and analysis of the urban heat island effect on soil in Nanjing, China. Environ. Earth Sci. 2012, 67, 215-229. [CrossRef]

268. Menberg, K.; Bayer, P.; Zosseder, K.; Rumohr, S.; Blum, P. Subsurface urban heat islands in German Cities. Sci. Total Environ. 2013, 442, 123-133. [CrossRef] [PubMed]

269. Qiao, Z.; Zhang, D.; Xu, X.; Liu, L. Robustness of satellite-derived land surface parameters to urban land surface temperature. Int. J. Remote Sens. 2018, 1-17. [CrossRef]

270. Tu, L.; Qin, Z.; Li, W.; Geng, J.; Yang, L.; Zhao, S.; Zhan, W.; Wang, F. Surface urban heat island effect and its relationship with urban expansion in Nanjing, China. J. Appl. Remote Sens. 2016, 10, 026037. [CrossRef] 
271. Meng, F.; Liu, M. Remote-sensing image-based analysis of the patterns of urban heat islands in rapidly urbanizing Jinan, China. Int. J. Remote Sens. 2013, 34, 8838-8853. [CrossRef]

272. Kamruzzaman, M.; Deilami, K.; Yigitcanlar, T. Investigating the urban heat island effect of transit oriented development in Brisbane. J. Transp. Geogr. 2018, 66, 116-124. [CrossRef]

(C) 2018 by the authors. Licensee MDPI, Basel, Switzerland. This article is an open access article distributed under the terms and conditions of the Creative Commons Attribution (CC BY) license (http://creativecommons.org/licenses/by/4.0/). 